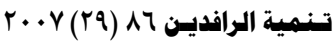

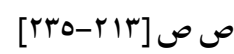

$$
\begin{aligned}
& \text { المؤثرات الفائقة في حركة أسعار الأسهم }
\end{aligned}
$$

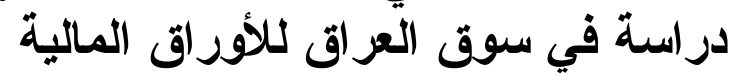

$$
\begin{aligned}
& \text { الاكتور إلياس خضير فنوش } \\
& \text { مدرس - قسم العلوم المالية والمصنية فوفرفية } \\
& \text { كلية الادارة و الاقتصاد - جامعة الموصل } \\
& \text { Elyais2009@yahoo.com }
\end{aligned}
$$

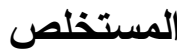

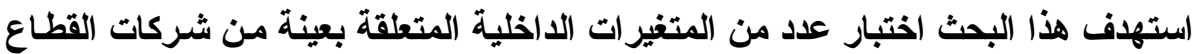

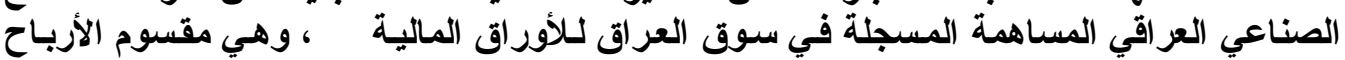

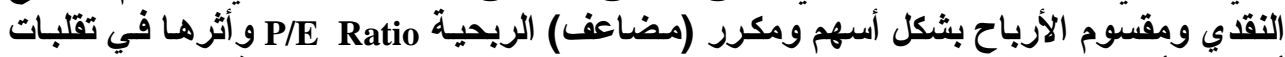

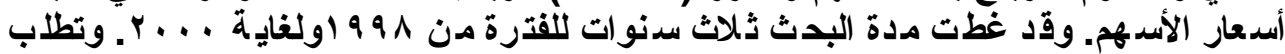

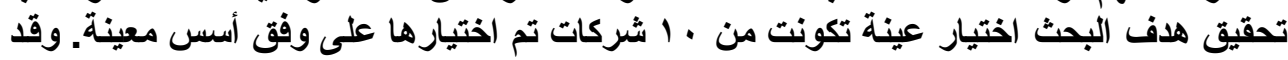

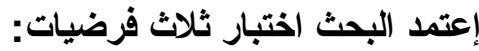

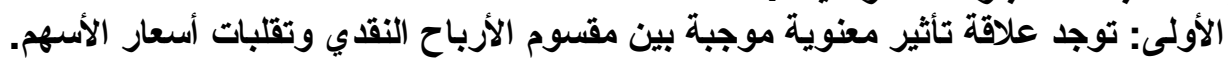

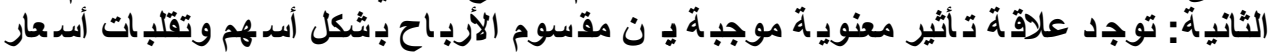
الأسهر. الثالثة: توجد علاقة تأثير معنوية موجبة بين مكرر (مضاعف) الربحية وتقلبات أسعار الأسهم.

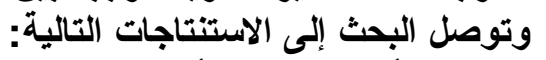

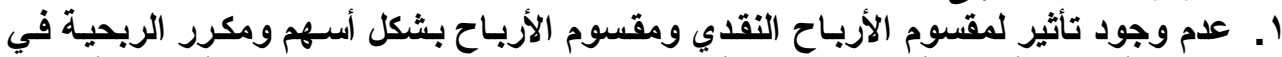

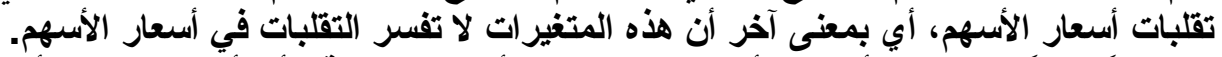

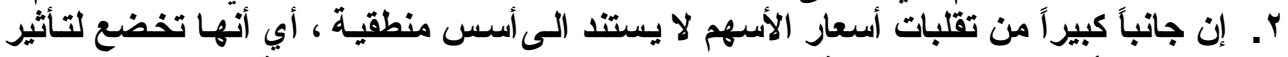

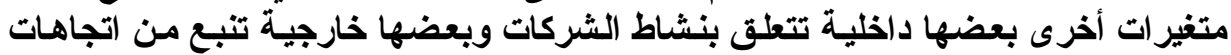

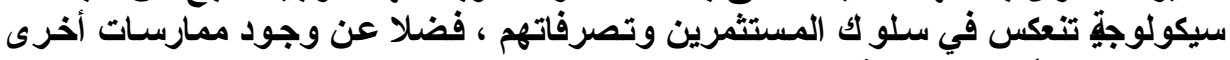
تحدث داخل الأسواق المالية. 


\title{
The Volatile Effect on Stock Prices Movements A Study of Iraqi Stock Market
}

\author{
Ilyas Kh. Fannoush (PhD) \\ Lecturer-Department of Financial Sciences \\ University of Mosul
}

\begin{abstract}
The research aimed at testing many of internal variables which related to sample from Iraqi industrial sector companies that registered in Baghdad Stock Exchange. Those are cash dividend profits, dividend profits as stocks, and P/E ratio, and those effects in stocks price vicissitudes. The time period covered three years from 1998-2000.

The achievement of research purpose required select the samples consisting of 10 industrial companies which have been choose it on certain bases. This research depended on three hypotheses:

First: There is a significant relation between cash dividend profits and stocks prices vicissitudes.

Second: There is a significant relation between dividend profits as stocks and stocks prices vicissitudes.

Third: There is significant relation between $\mathrm{P} / \mathrm{E}$ Ratio and stocks prices vicissitudes.

The study reached to some conclusions:

1. Cash dividend profits, dividend profits as stocks and P/E Ratio don't have any effect on stocks prices vicissitudes, in the other mean this variable don't expression the a vicissitudes in stocks prices .

2. A big side from stocks prices vicissitudes are not depend on logical basics, and stand to other features effected, some of them are internal related by companies activities.

Some of them are external come from psychologist trend reflection in behavior and manners of investors, and there is anther process which happen inside the financial markets.

$$
\begin{aligned}
& \text { المقدمة }
\end{aligned}
$$

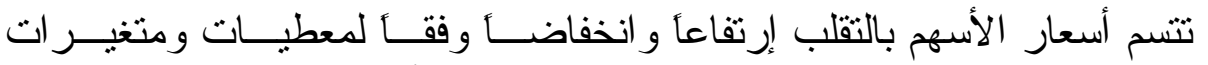

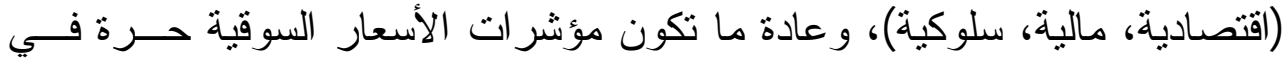

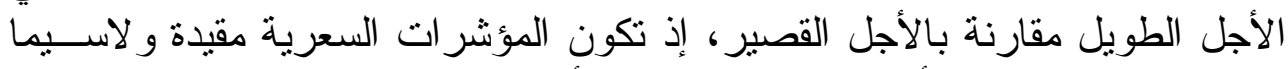

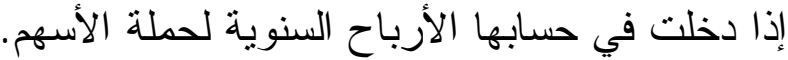

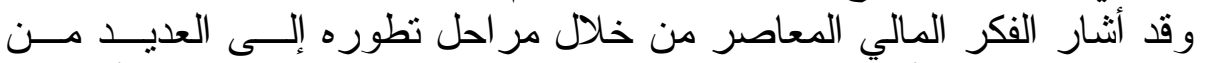

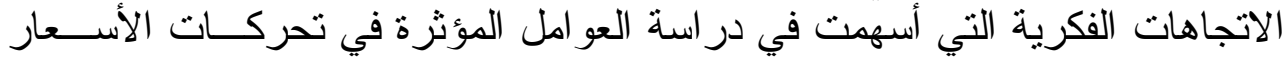

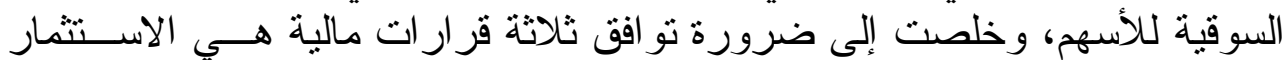

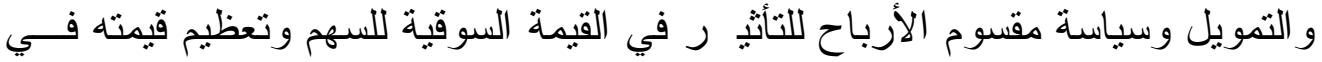

$$
\begin{aligned}
& \text { السوق. }
\end{aligned}
$$

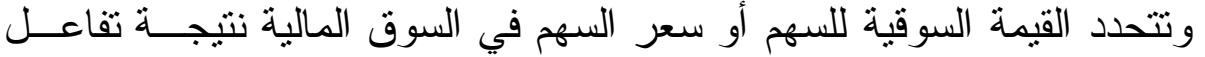

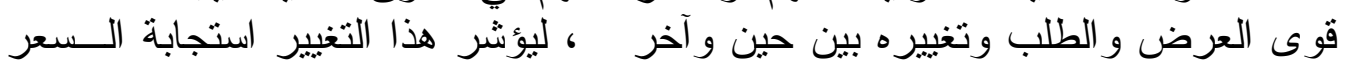




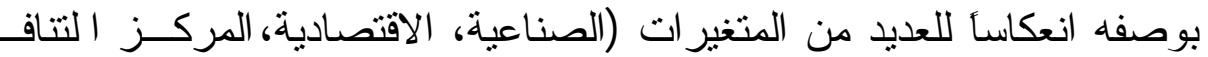
اتجاهات الإدارة بالنمو في المستقبل). (Branch, 1989, 208)

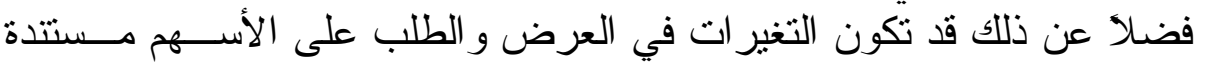

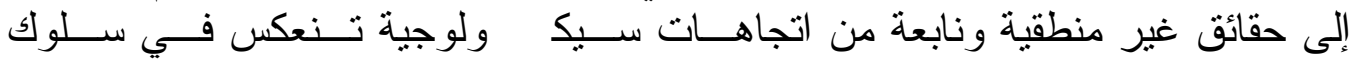

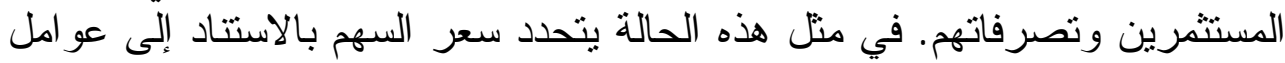
شخصية.

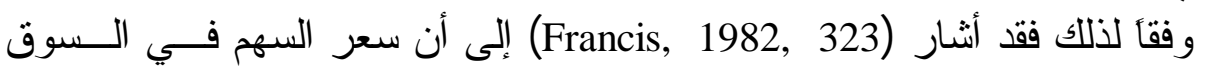

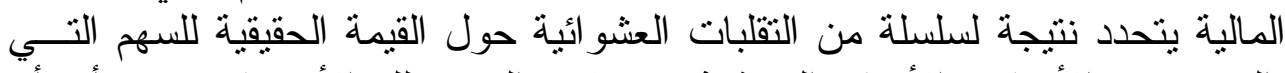

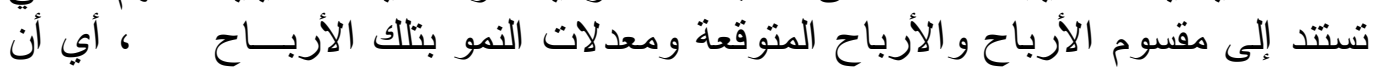

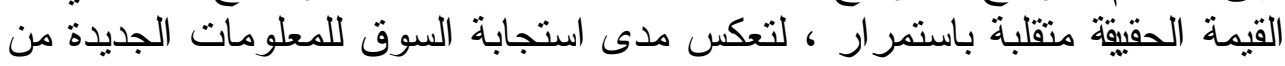

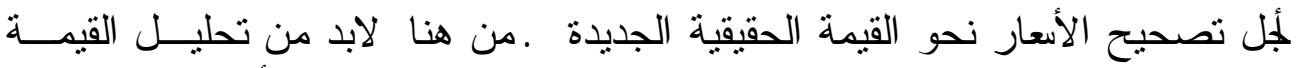

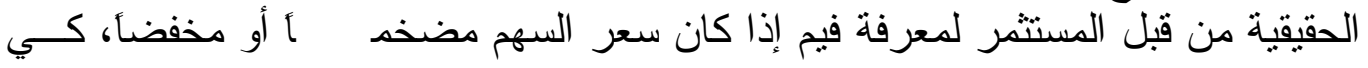
يتمكن من توقيت قر اره الاستثماري (Hampton, 1996, 368).

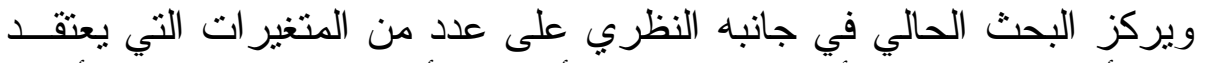

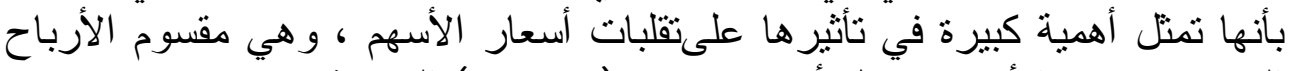

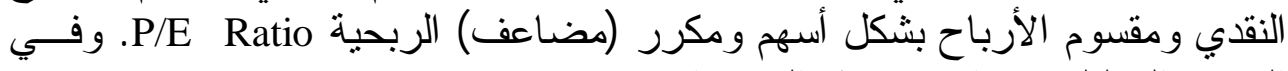
الجانب التحليلي يتم اختبار هذه الإح بـنغير المنغير ات.

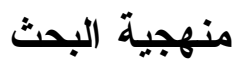 \\ أولاًا - مشكلة البحث البه}

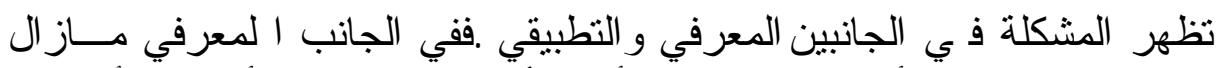

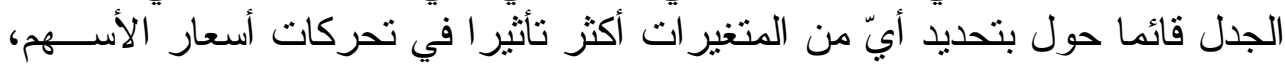

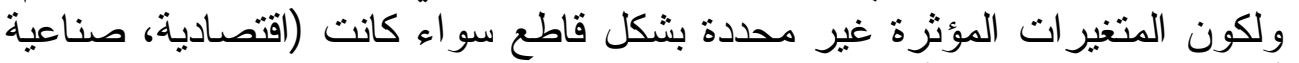

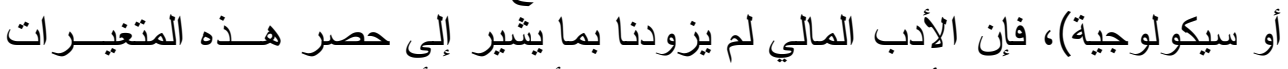

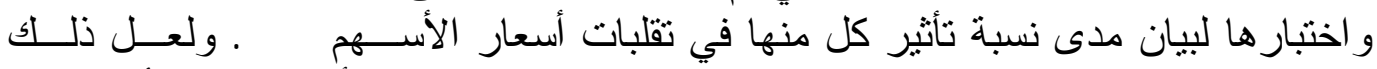

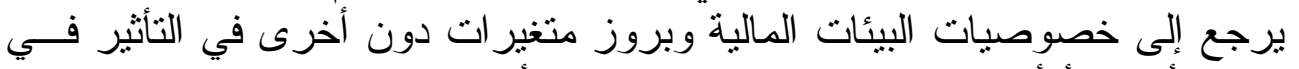

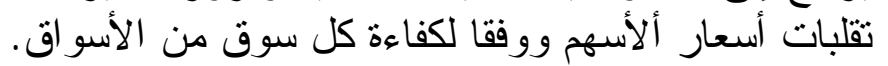

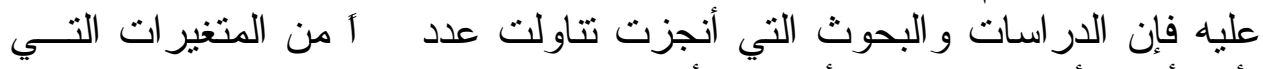

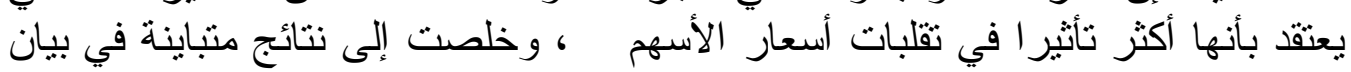
مدى التأثير من عدمه الكئ.

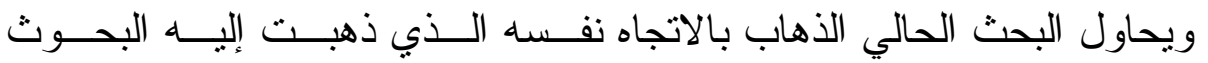

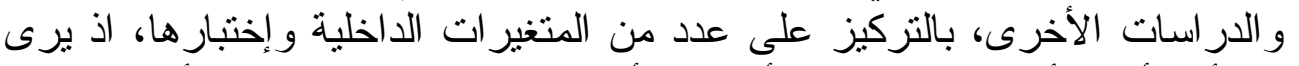

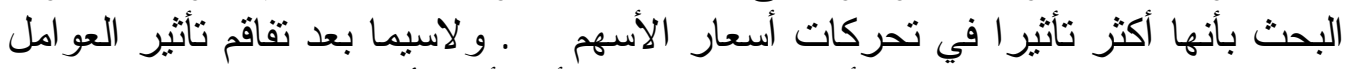

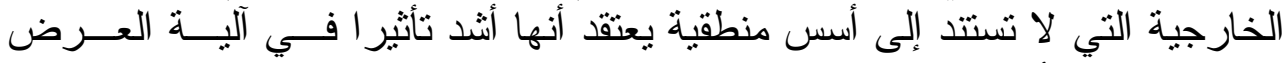
و الطلب على الأسهم، وهذا ما يقودنا إلى القول بوجود المشكلة في جانبها التطبيقي. 


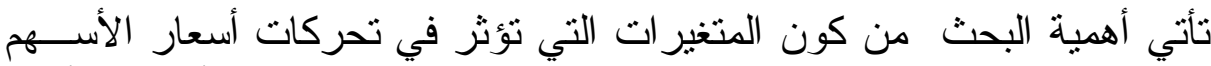

\section{ثانياً - أهمية البحث}

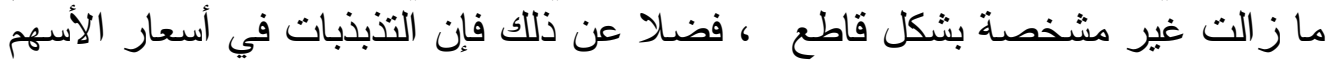

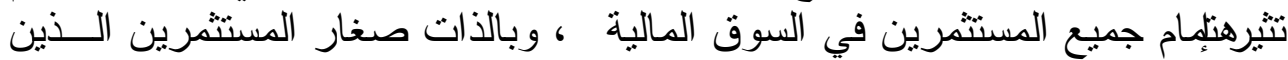

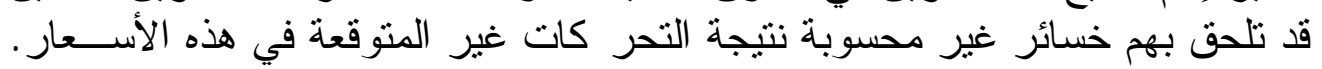

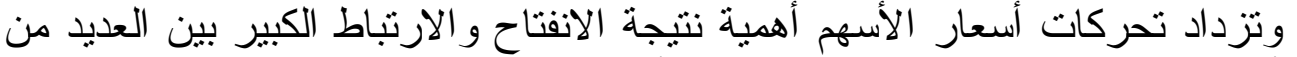

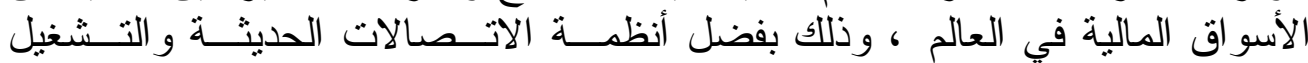

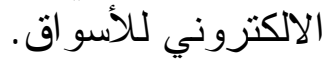

$$
\begin{aligned}
& \text { ثالثاً - هدف البحث } \\
& \text { يهدف البحث الوصول البحث إلى ما يأتي: }
\end{aligned}
$$

ا ـ اختبار مدى إمكانية انسجام بعض المعطيات النظريــة للموضــــوع عاتجاهاتهـــا المختلفة مع ما يحدث في السوق المالية العر اقية من تغير التهية الت في أسعار الأسهم.

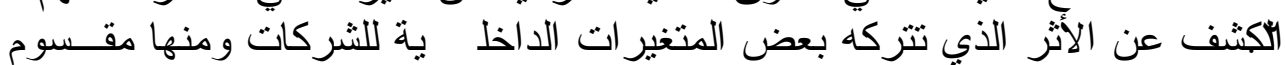

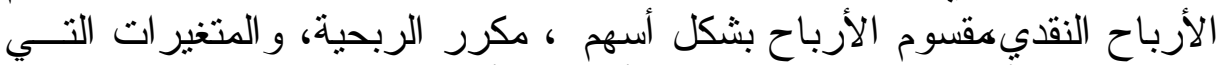

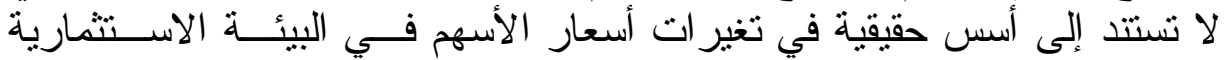

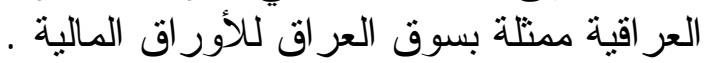

$$
\text { رابعاً - نموذج البحث }
$$

يوضح الشكل الآتي متغير ات البحث التي تشمل نو عين من المتغير ات.

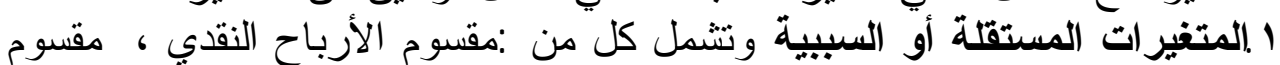

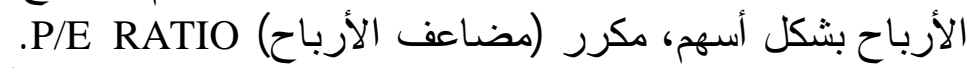

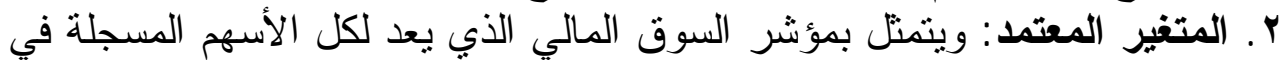

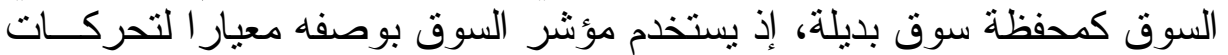

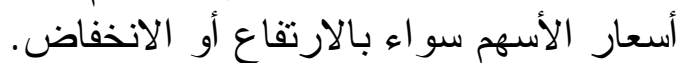

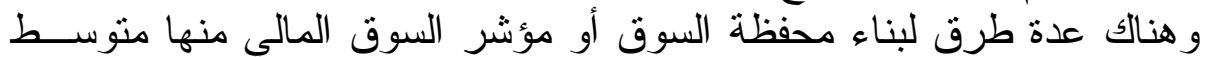

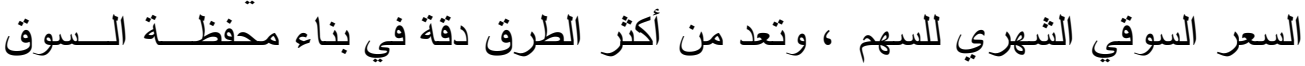

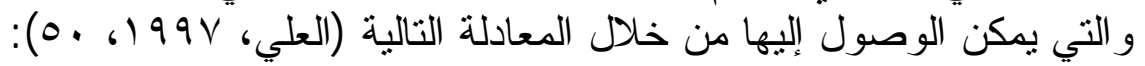

متوسط السعر = مجموع حاصل ضرب كل صفقة تداول نفذت على السهيه X اعدد الأسهم في كل صفقة مجموع عدد الأسهر المتداولة خلا الثهر الألهر السوقي للسهم

غير أنه تعذر استخدام هذه الطريقة لعدم إمكانية الحــصول علــى البيانــات الخاصة بكل صفقة تداول و عدد الأسهم في كل صفقة الطنة

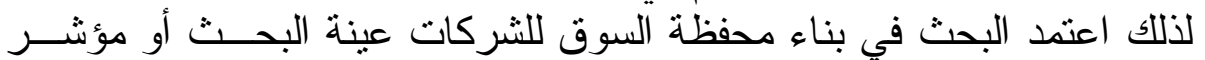
السوق للعينة على متوسط سعر الإغلاق الشهري لأسعار الأسهر. 


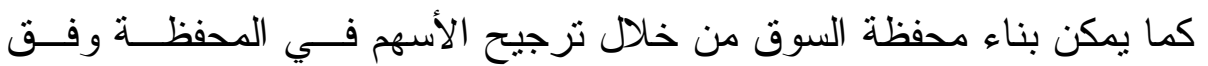

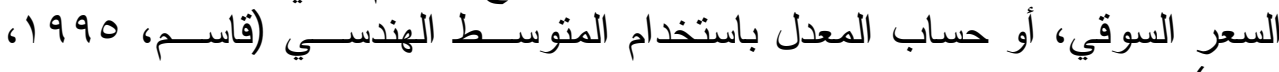

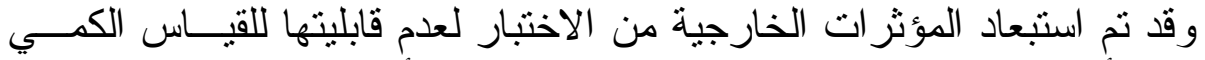

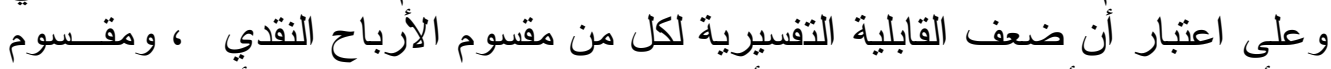

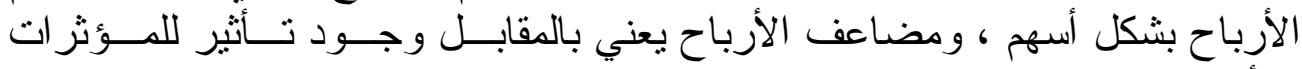

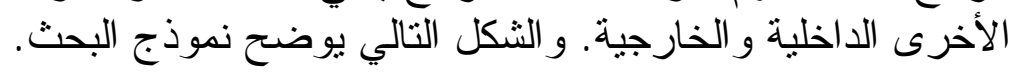

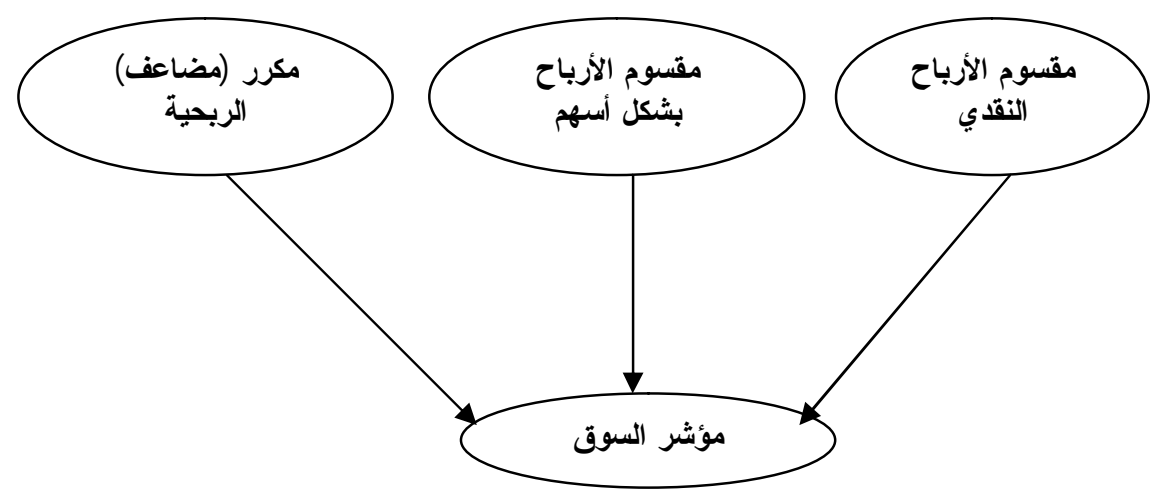

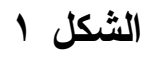 \\ إنموذج البحث}

خامساً - فرضيات البحث

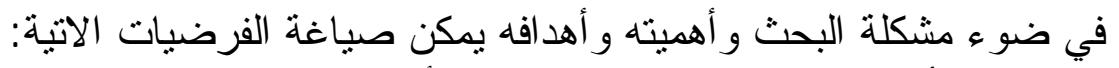

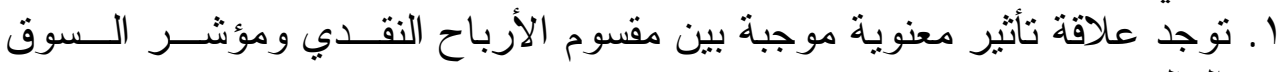

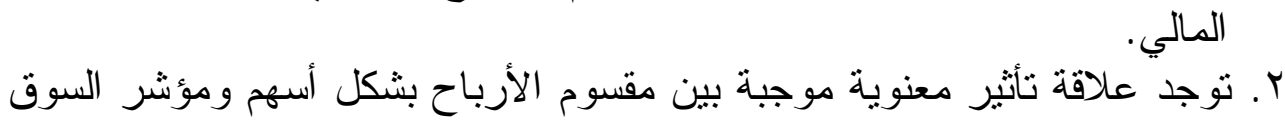
تلو.جد علاقة تأثير معنوية موجبة بين مكرر (مضاعف) الأربــاح P/E ومؤشــر السوق المالي.

\section{سادساً - عينة البحث ومدته الته}

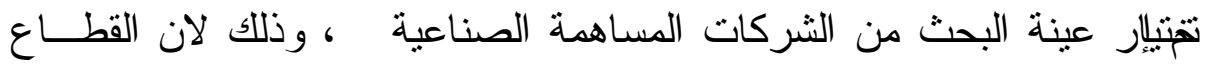

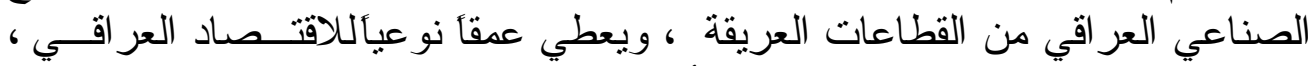

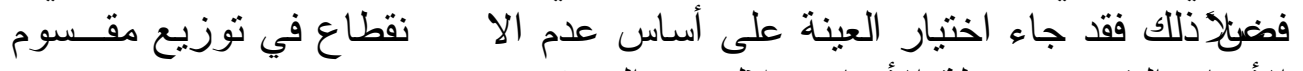
الأرباح النقدي ورسملة الأرباح خلال مدة البحث. 


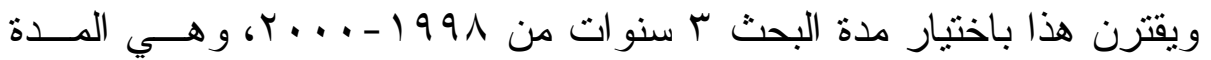

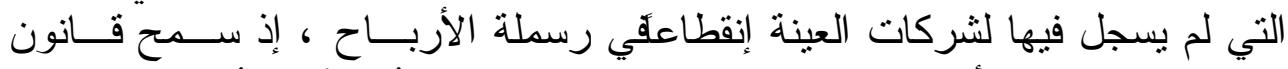

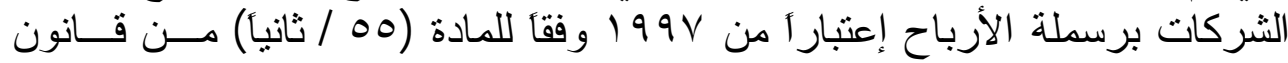

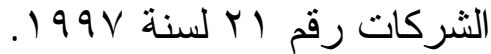
و الجدول الاتي يوضح الثركات عينة البحث.

\begin{tabular}{|c|c|c|c|c|}
\hline \multicolumn{5}{|c|}{ الشركات عينة البحث } \\
\hline النوعنيف & طبيعة الملكية & التأسيس & اسم الشركة & $ت$ \\
\hline نسيجية & مساهمة خاصة & 1919 & العر اقية للسجاد و المفروشات & 1 \\
\hline نسيجية & مساهمة خاصة & 1919 & الخياطة الحديثة & r \\
\hline غذائية & مساهمة خاصة & 1919 & المشروبات الغازية و المعدنية للمنطقة الثمالية & r \\
\hline هندسية & مساهمة مختلطة & 1974 & الهلال الصناعية & $\varepsilon$ \\
\hline هندسية & مساهمة مختلطة & $19 \vee \varepsilon$ & الصناعات الخفيفة & 0 \\
\hline كيماوية & مساهمة مختلطة & 1974 & الوطنية للصناعات الكيماوية و البلاستيكية & 7 \\
\hline هندسية & مساهمة مختلطة & $19 \vee r$ & الصناعات الالكترونية & $\checkmark$ \\
\hline كيماوية & مساهمة مختلطة & $19 \vee 7$ & صناعات الأصباغ الحديثة & $\wedge$ \\
\hline هندسية & مساهمة مختلطة & $197 \varepsilon$ & الوطنية للصناعات المعدنية و الدر اجات & 9 \\
\hline غذائية & مساهمة خاصة & $190 \leqslant$ & البيرة الثرقية & 1. \\
\hline
\end{tabular}

\section{أولاً - مقسوم الأرباح النقاب وتقلبات أسعار الأسهر}

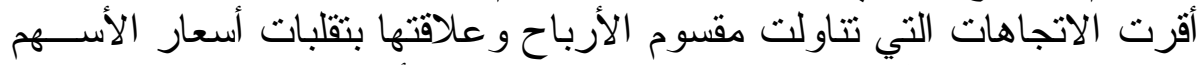

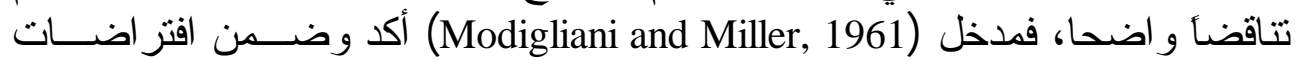

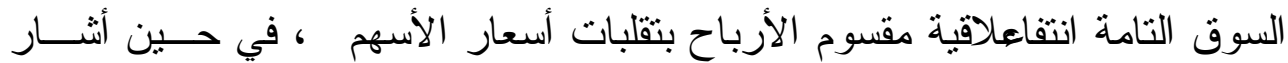

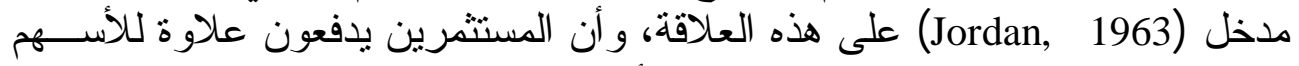
التي تحصل على نسبة عالية من مقسوم الأرباح.

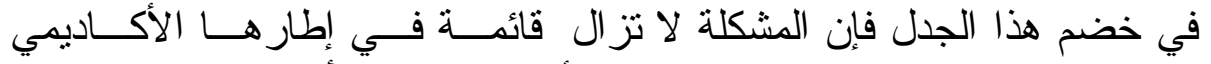

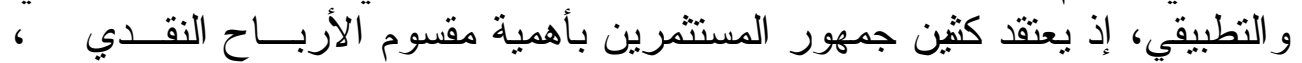

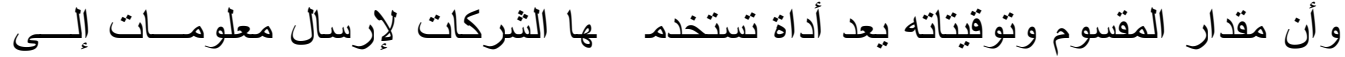

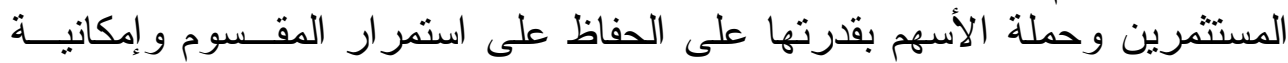

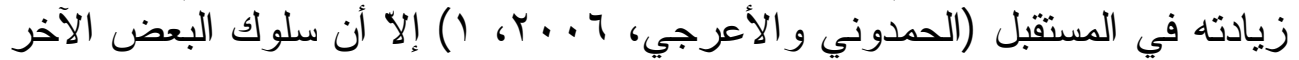

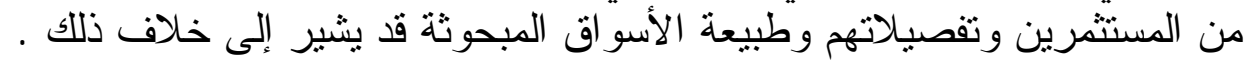


ويشير (Petty, 1982, 484) إلى أن جانباً كبير أ من تقلبات أسعار الأسهم يأتي

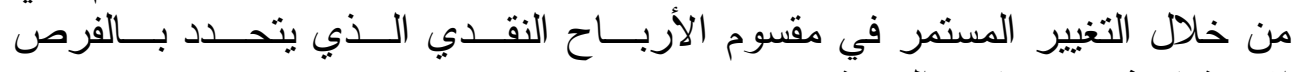
الاستثمارية وتفضيلات المستثمرين.

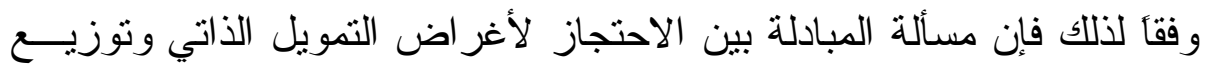

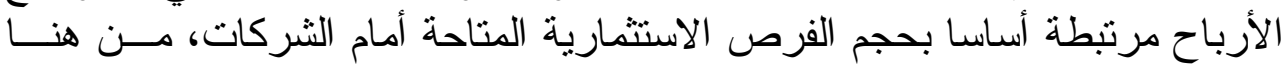
فإن طبيعة سياسة مقسوم الأرباح تتحدد وفقا لما لأيأني (Van Horn, 1986, 324):

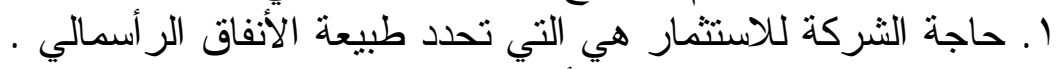

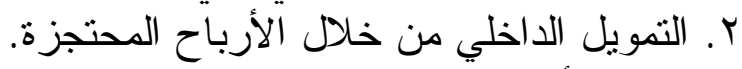

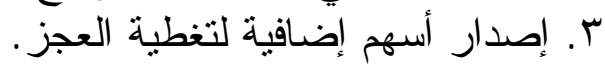
ع. توزيع الفضلة من الأرباح على المساهمين.

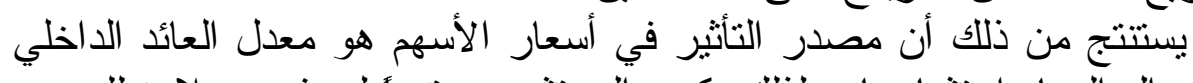

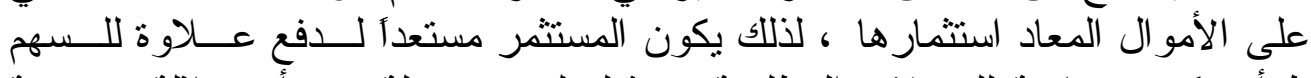

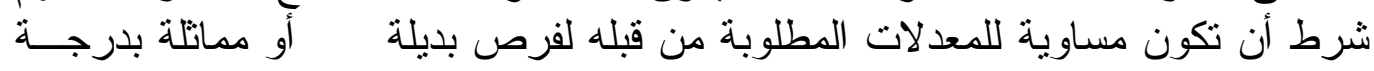
المخاطرة

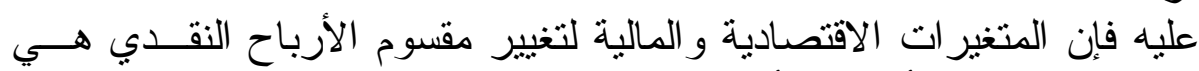

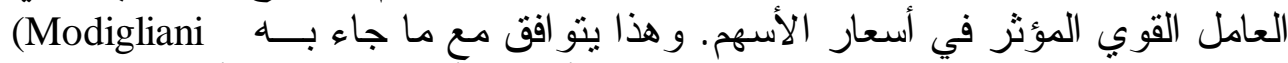
and Miller)

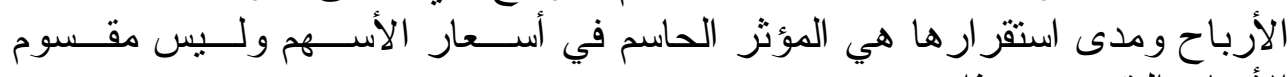
الأرباح النقدي بحد ذاته.

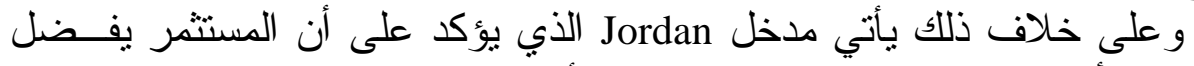

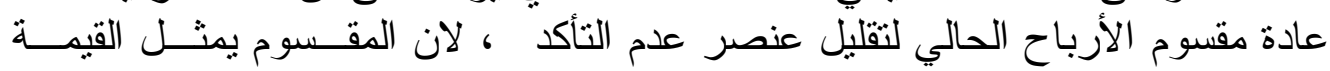

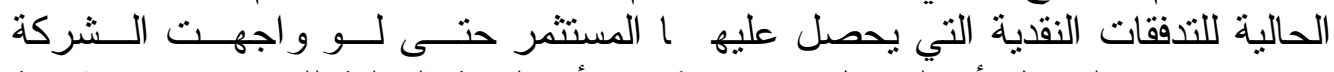

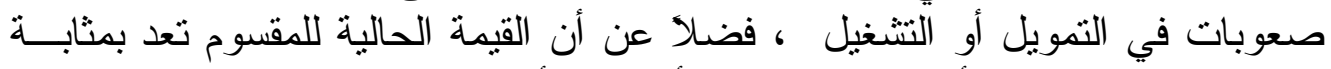

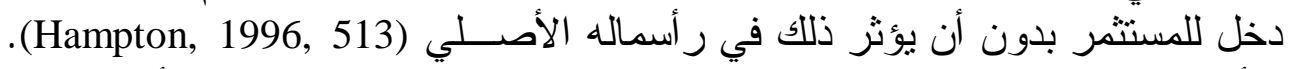

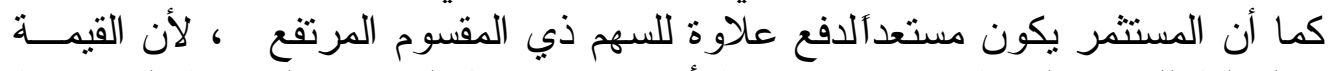

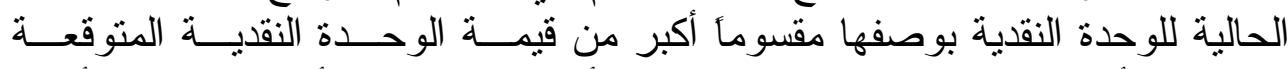

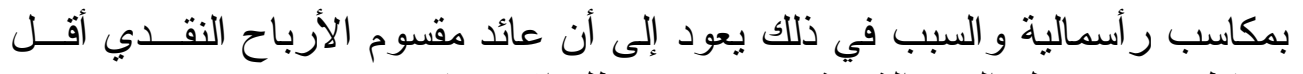

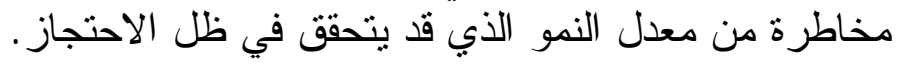

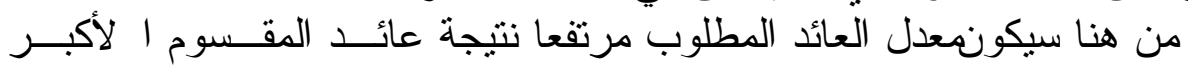

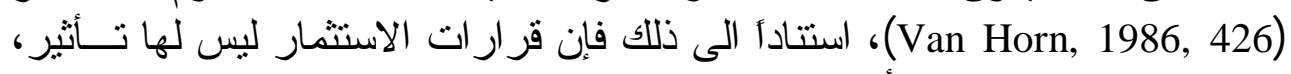

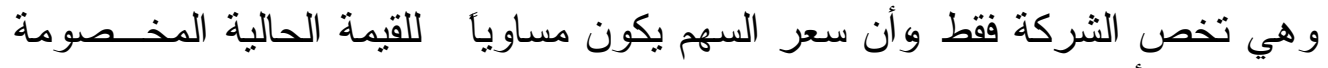
لمقسوم الأرباح المتوقع في المستقبل. 
ثانياً - مقسوم الأرباح بشكل أسهم وتقلبات أسعار الأسهم

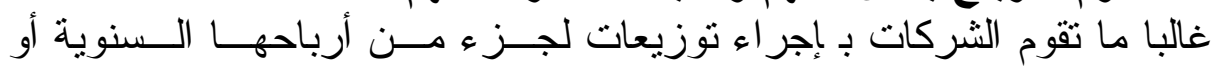

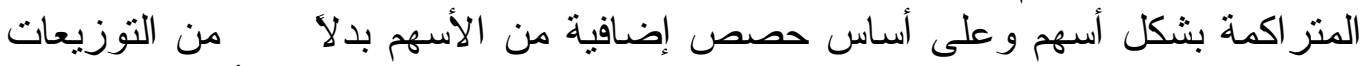
النقدية، و هذه العملية ببساطة عبارة عن تحويل دفتري من حساب الأرباح المحتجزة التهن لحساب رأس المال.

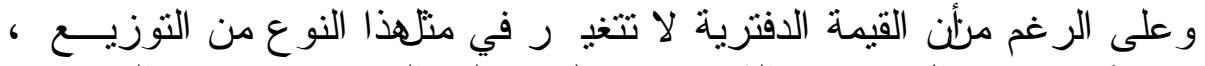

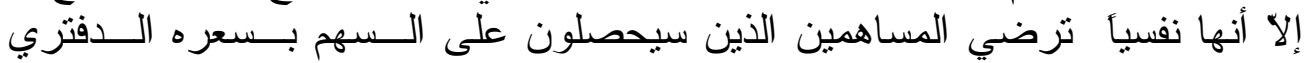

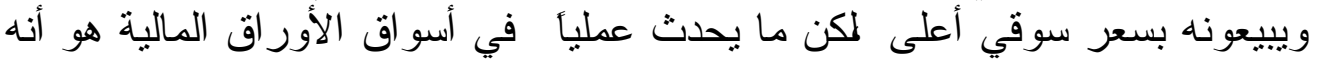

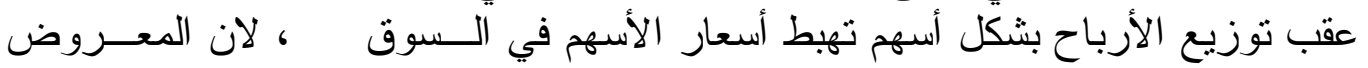

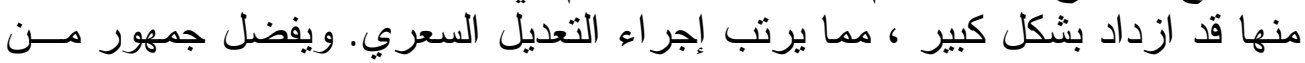

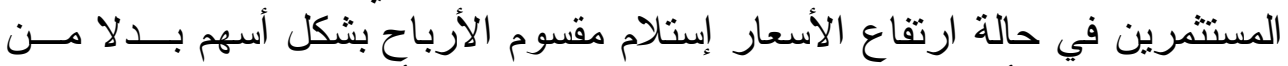
المقسوم النقدي للأرباح لتقوق العائد المتحقق في الحالة الأولى مقارنة بالثانية.

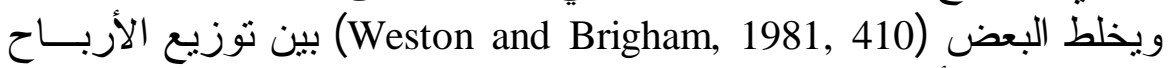
بشكل أسهم وتجزئة الأسهر Stock Dividends and Stock Splits.

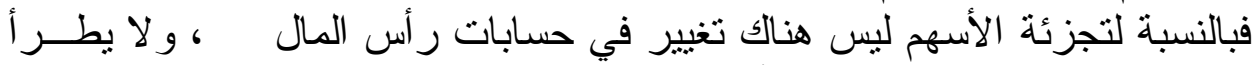

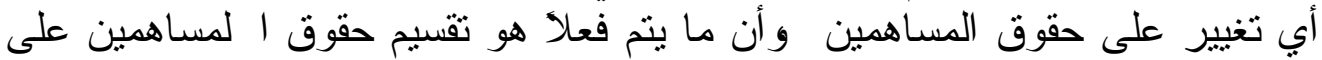

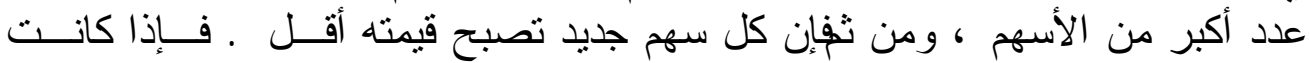

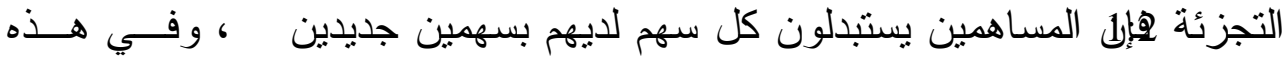
الحالة فإن القيمة الدفترية سوف تتخفض إلى النصف وكذلك التهن القيمة الاسمية.

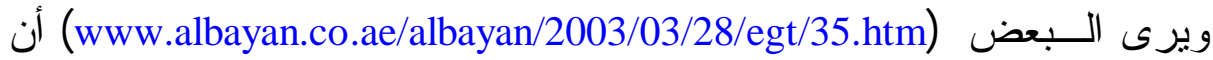

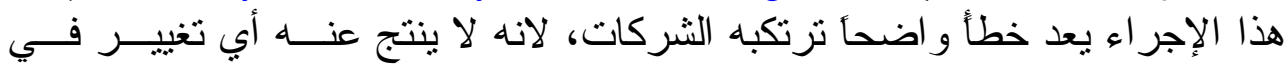

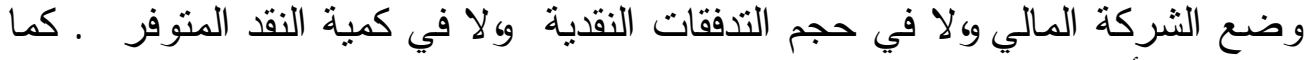

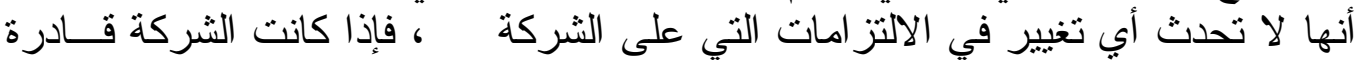

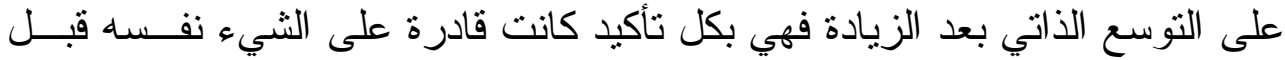

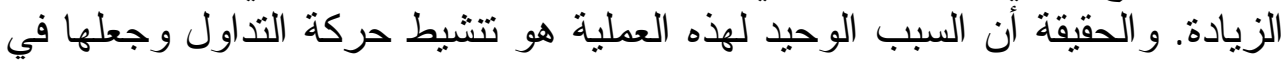

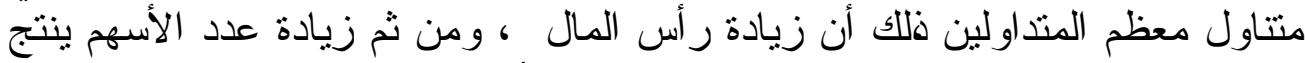

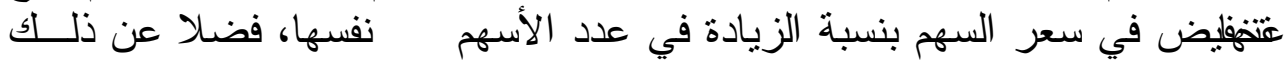

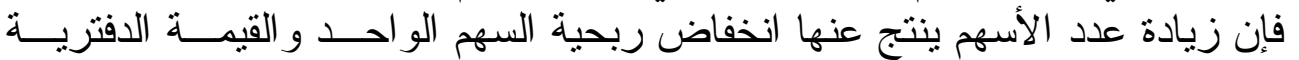

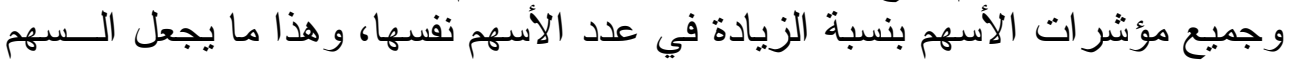

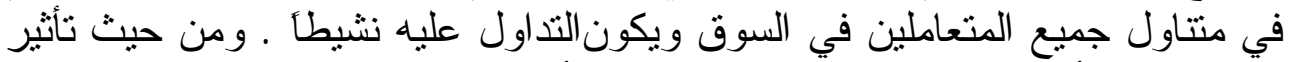

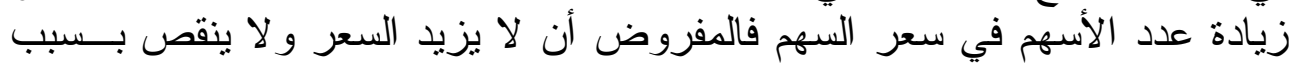

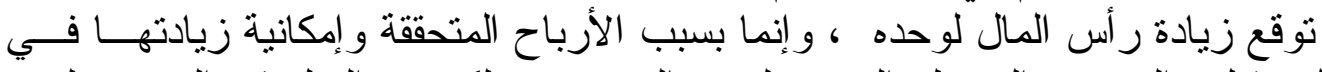

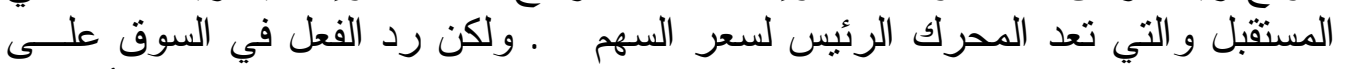

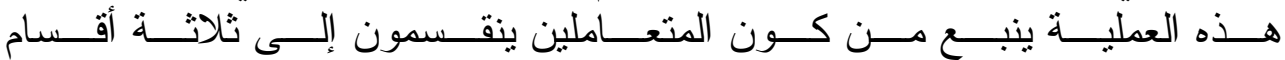
:(www.albayn.co.ae/albayn/2003/03/28/egt/35.htm) 
أ. متداولون بسطاء يعتقدون أنهم سيحصلون على أسهم إضافية بقيمة السهم نفـسها

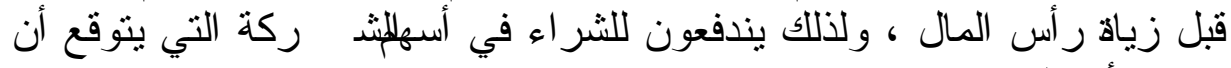
تزفع ر أسمالها. ب. مضاربون يستغلون أخبار زيادة رأس المال لرفع السعر وجني الأرباح.

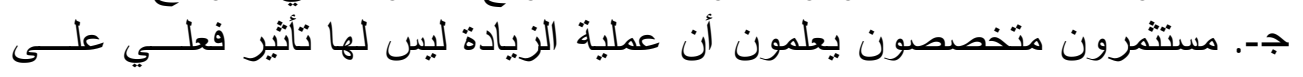

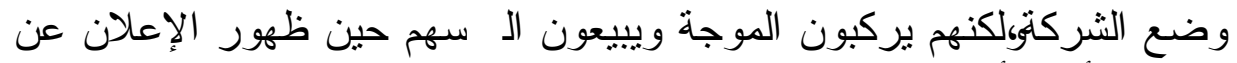

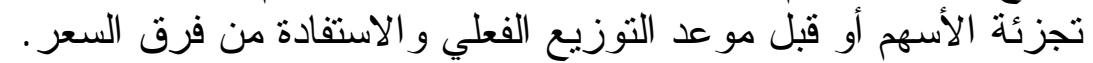
ويحسب السعر الجديد للسهم بعد عملية التوزيع وفقا للمعادلة الإنية الاتية:

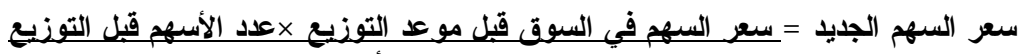 عدد الأسهم بعد التوزيع}

ومن وجهة نظر سوق نيويورك (Weston and Bregham,1981,410) هنــاكك

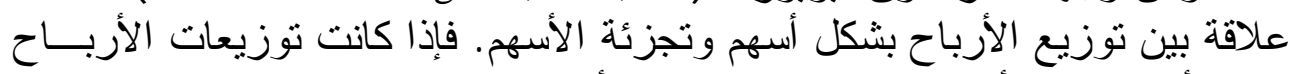

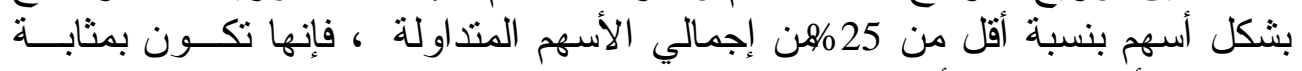
أما إذا كانت توزيعات الأرباح عند 25\% و أكثر من إجمالي الأسهم المتداولة فإنها تكون بمثابة تجزئة للأسهر.

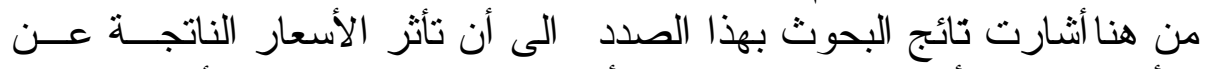

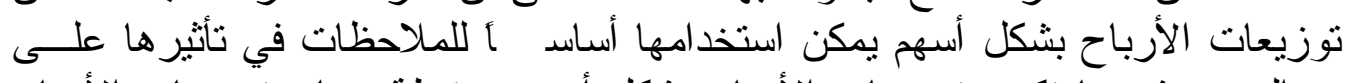

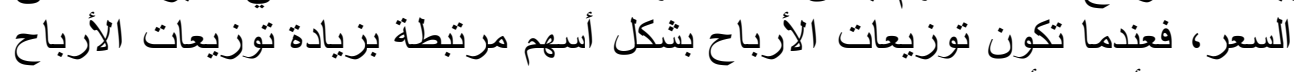

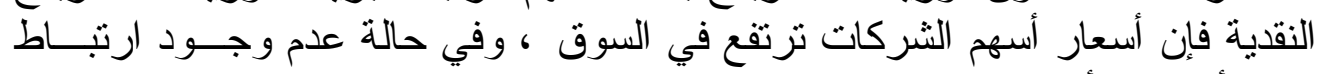

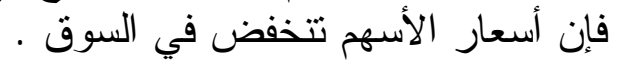

\section{ثالثاً - مكرر (مضاعف) P/E Ratio وعلاقته بتحركات أسعار الأسهم}

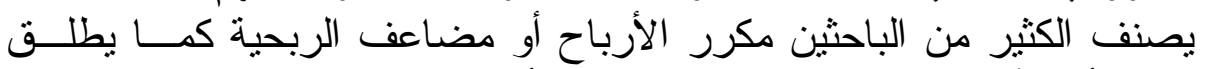

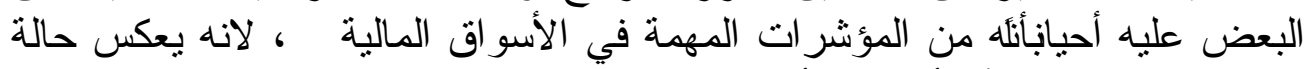

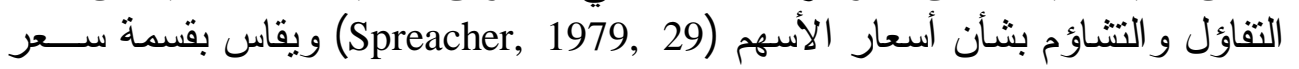

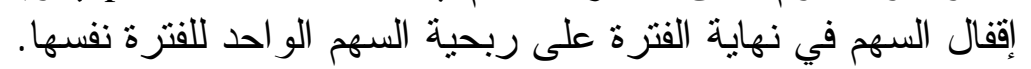

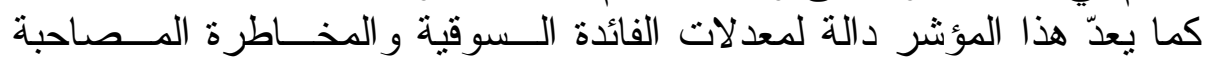

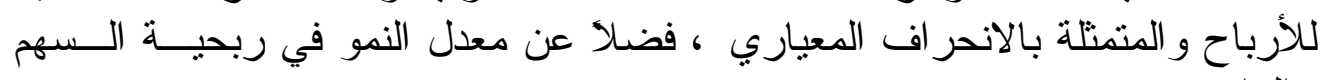
وترتبط نسبة P/E Ratio سلباً بمعدلات الفائدة السوقية و الانحر اف المعيـاري الو احد.

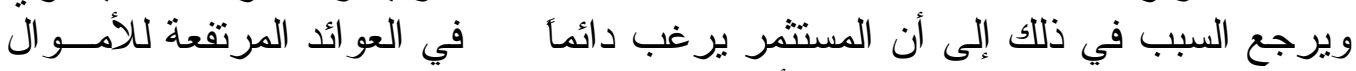

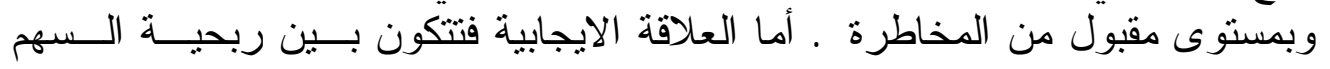


الو احد Eps و النمو في هذه الربحية حتى يمكن تبرير السعر المــفوع مــن قبــل المستثمر (William, 1974, 193).

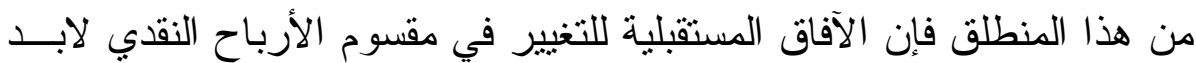

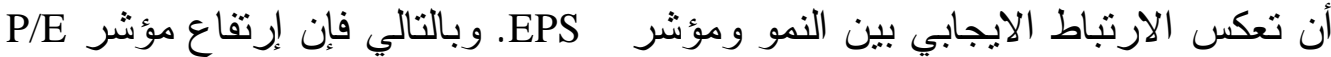

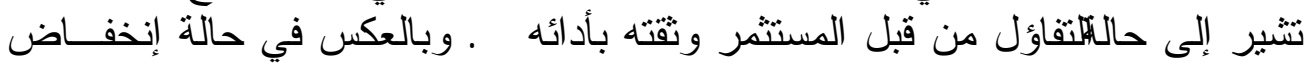

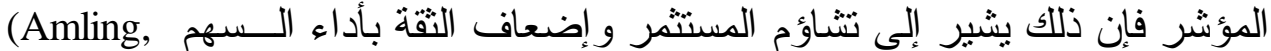
. 1974, 457)

وهناك إمكانية استخدام مدى استقر ار المبيعات ونسبة الر افعة المالية بوصــفها

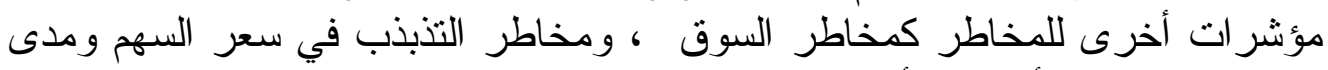
إرتباطه بحركة أسعار الأسهم في السوق السوق ل

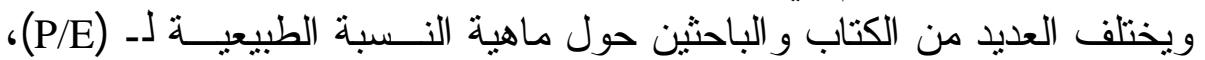

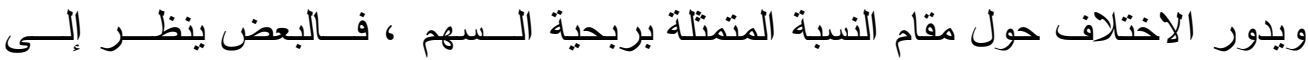

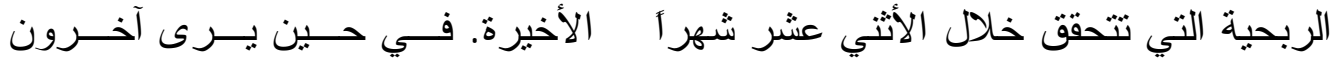
(Francis, 1991, 469) وليس على أساس ما تحقق في الماضي.

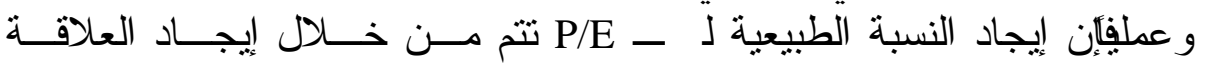

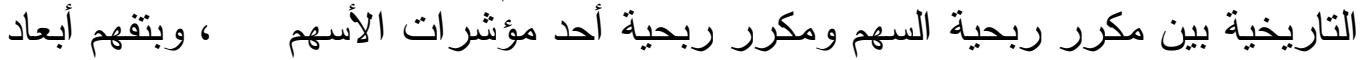

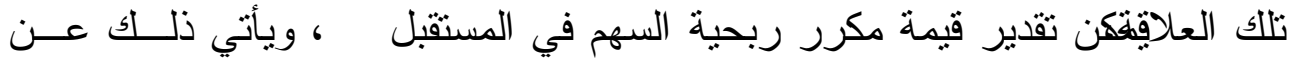

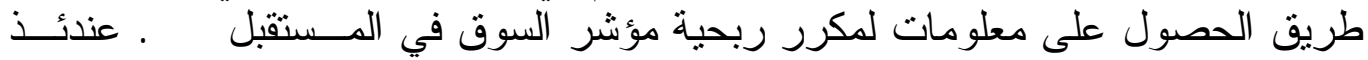

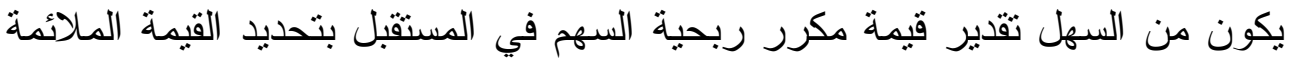
لمكرر ربحية مؤشر السوق.

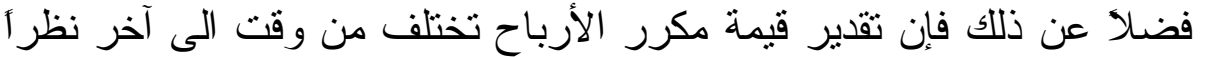

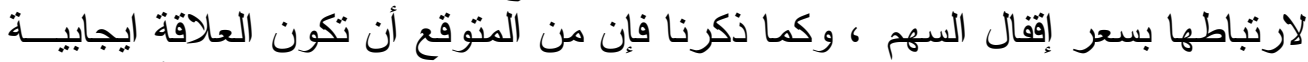

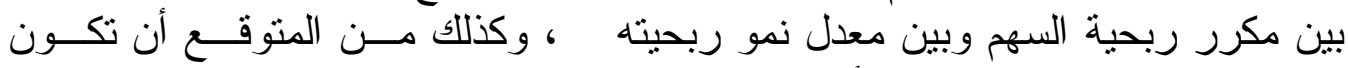

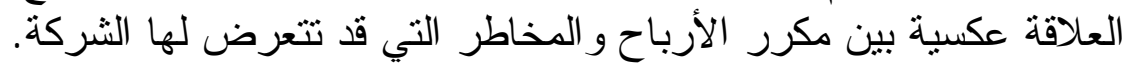

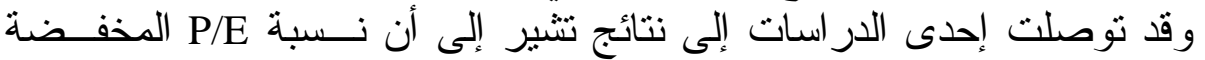

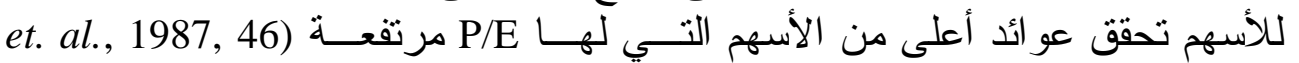

(Jahnke,

\section{رابعاً - المؤثرات الخارجية وعلاقتها بتحركات أسعار الأسهم دئ}

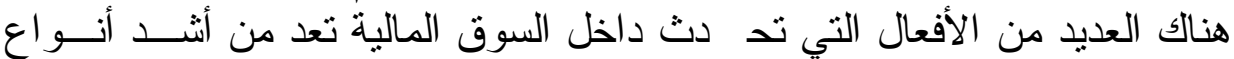

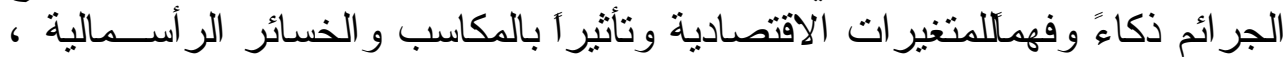

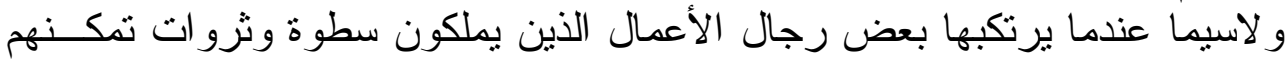

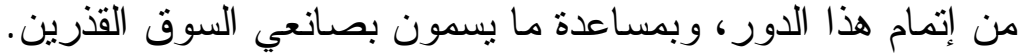




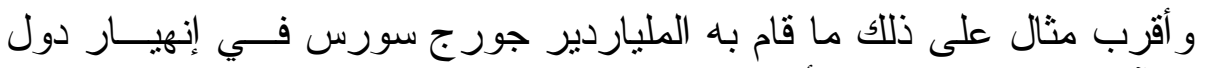

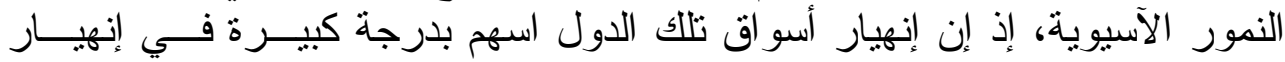

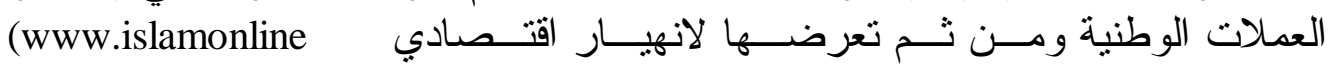
..net/Arabic/sitem ap.htm)

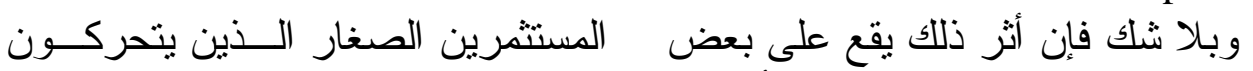

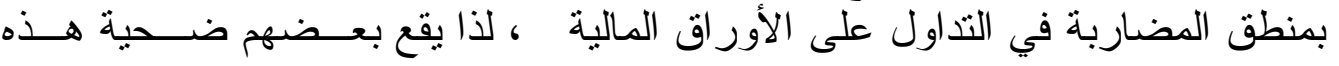

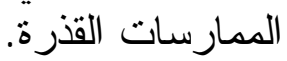
وتتعدد الممارسات القذرة التي تحدث في الأسو اق المالية ومنها:

\section{ا وـ فتح حسابات متعددة للتداول}

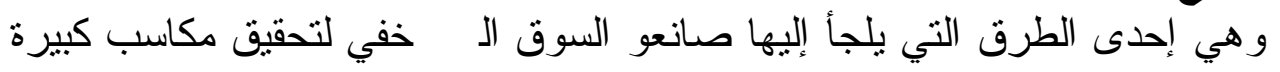

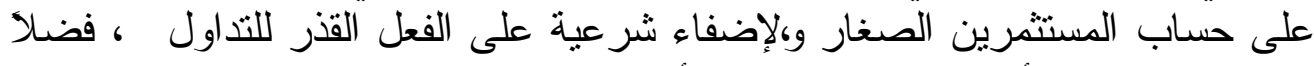

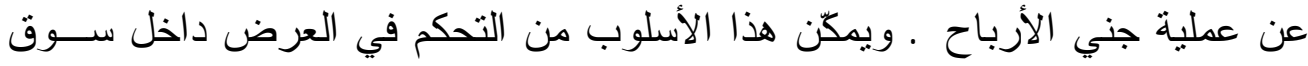

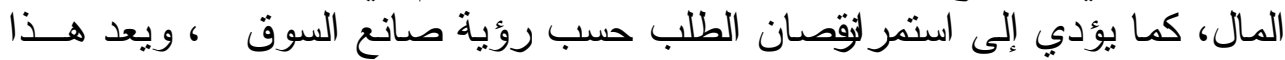

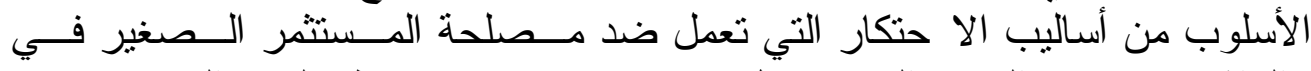

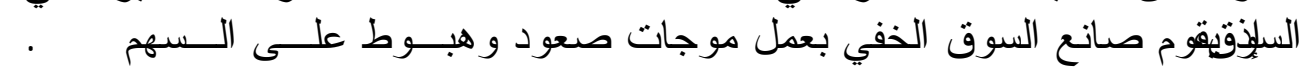
www.islamonline.net/Arabic/privacy.sht ml

\section{r ب أسلوب الصدمات السعرية}

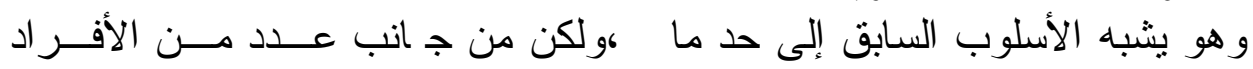

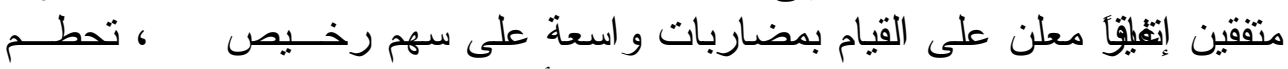

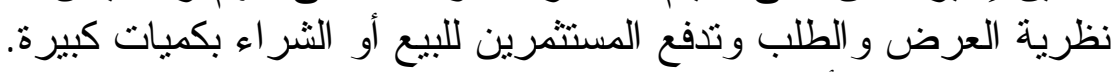

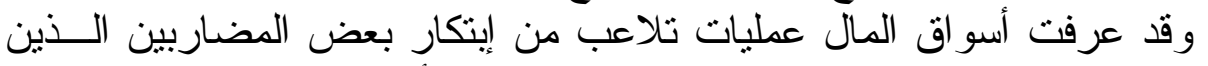

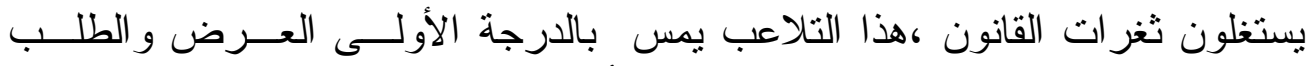

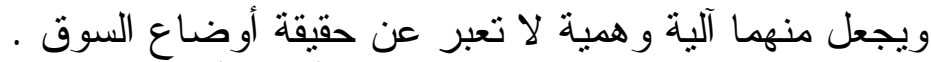

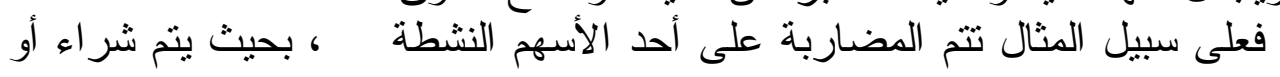

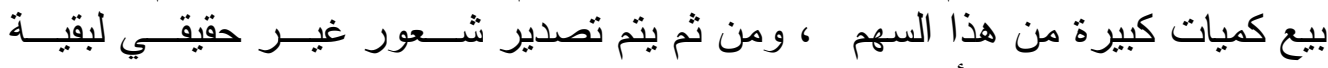

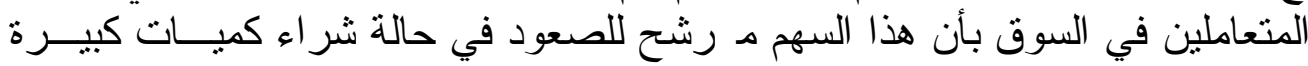

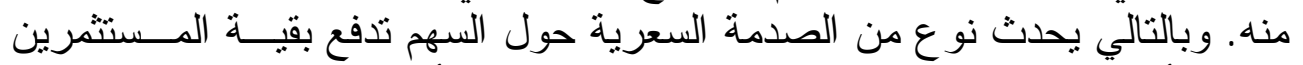

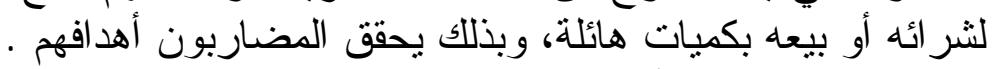

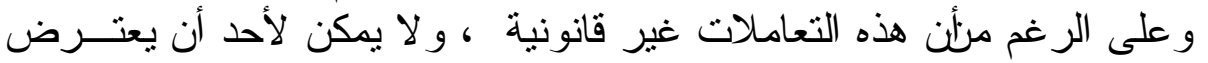

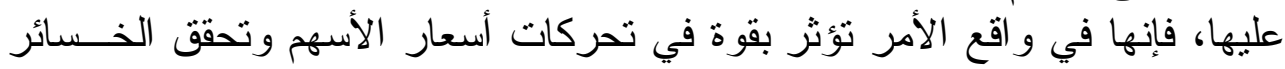

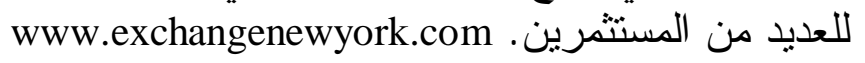


r. المضاربات الوهمية

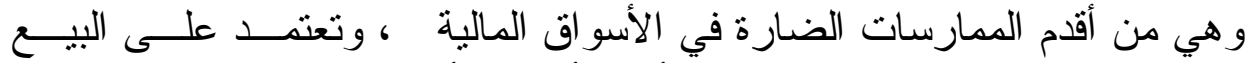

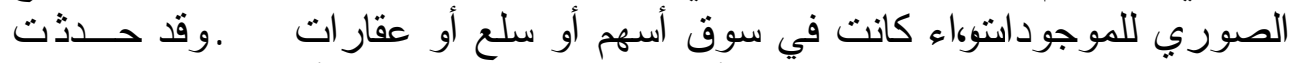

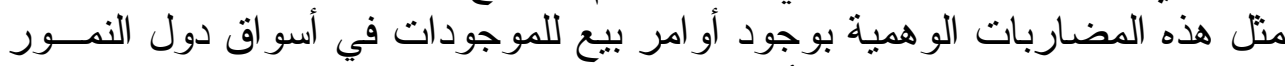

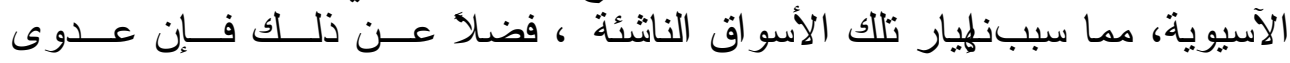

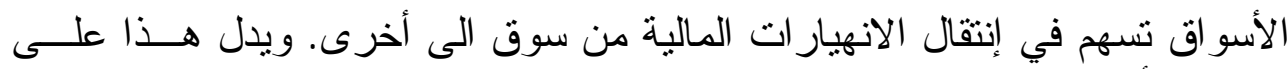

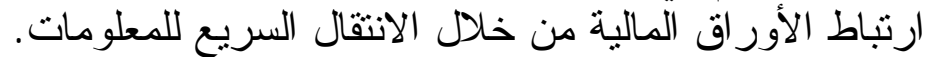

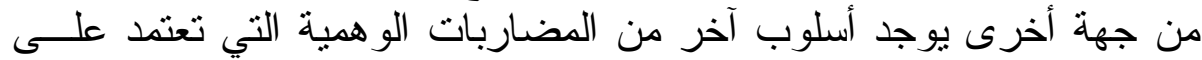

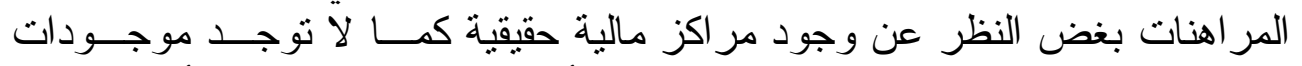

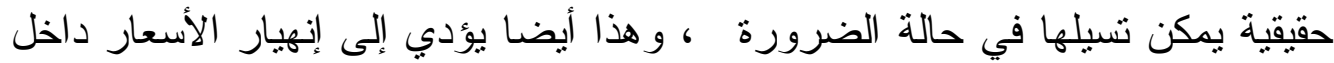
السوق www.thegulfbiz.com/vb/showwth

\section{ع. التّلاعب في نقل المعلومات}

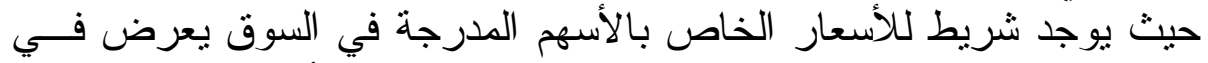

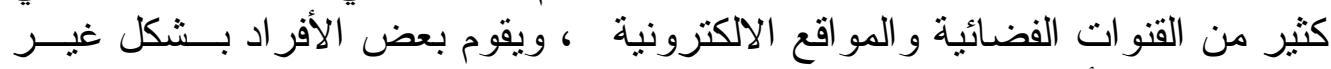

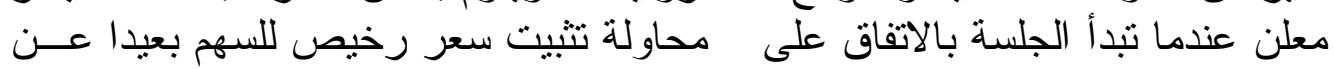

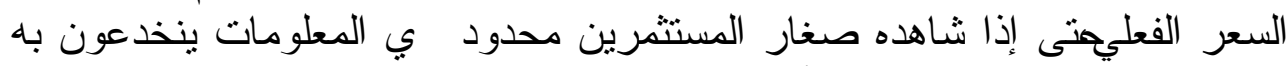

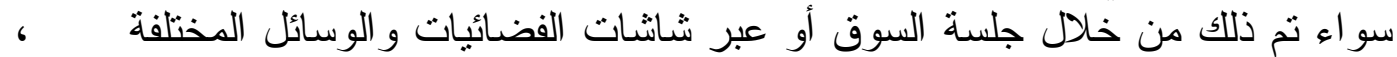

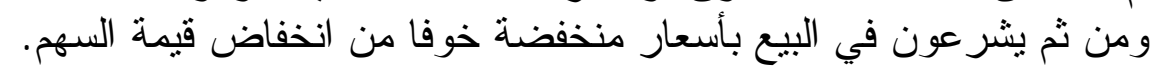

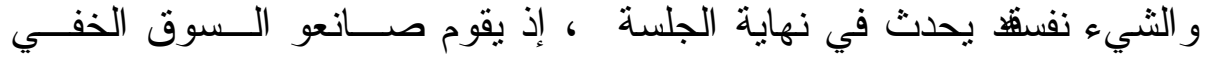

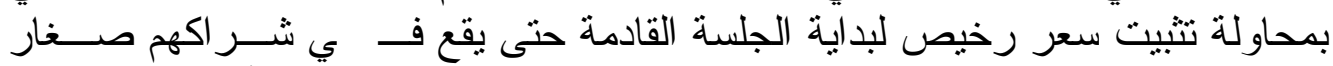

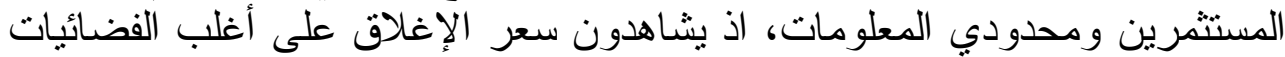

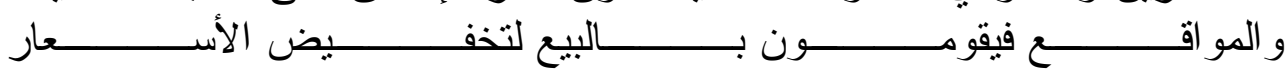
http://www.arabiyat.com/forums/foru....php? forumid=27.

0. تسريب المعلومات الخاطئة والشائعات

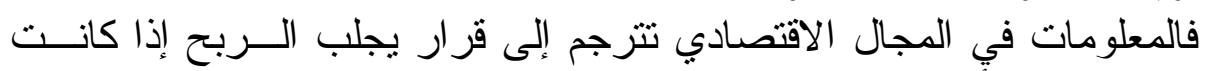
صحيحة، ويضيع رأس المال إذا كانت خاطئة (Francis, 1983,92). وصانعو السوق الخفي يع دون فو اعد اللعبة الدانة هنا بسيطة ما دامت أجهزة الرقابة

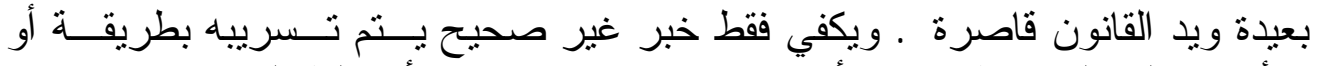

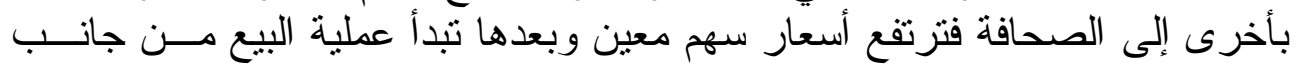

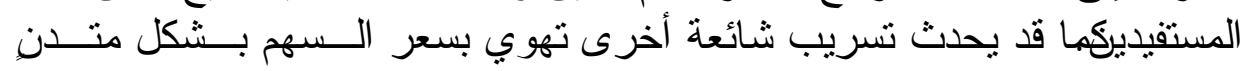

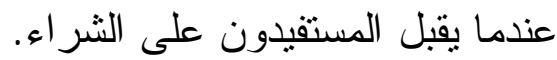

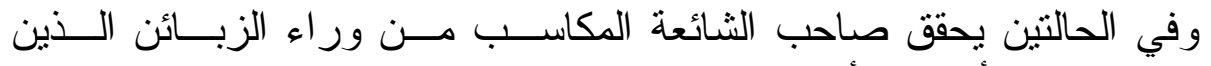

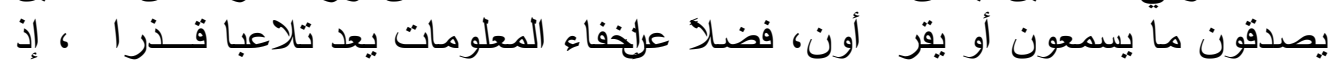




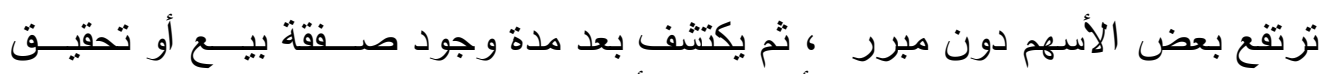

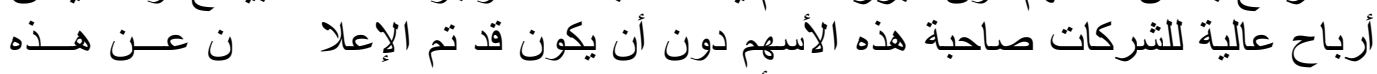

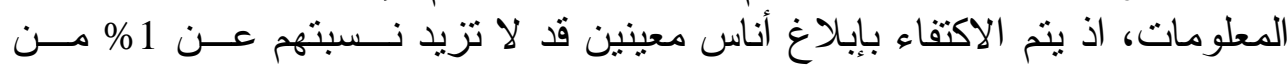

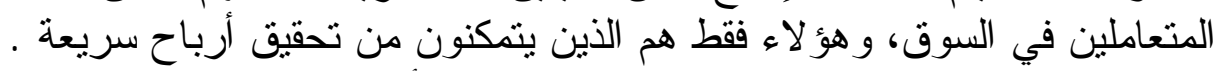

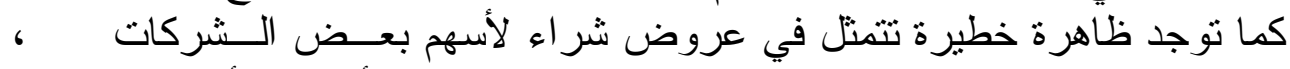

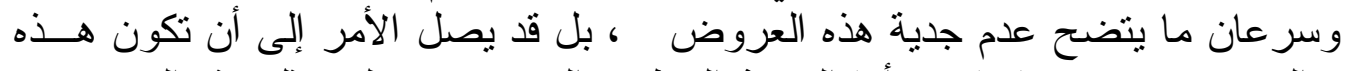

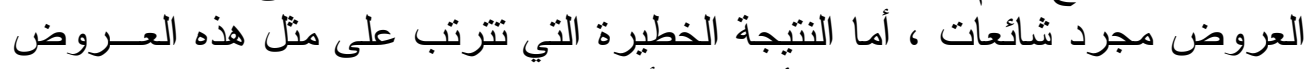

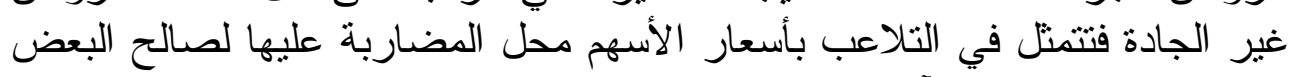

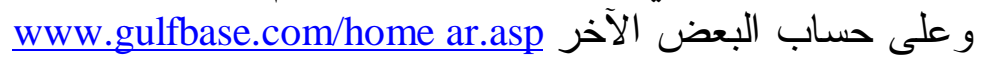

\section{7. تلاعب شركات السمسرة}

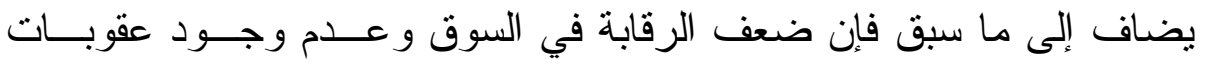

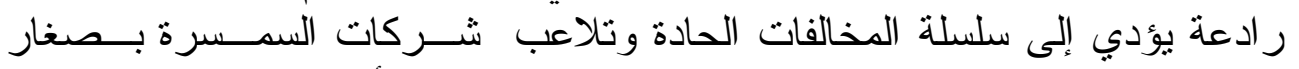

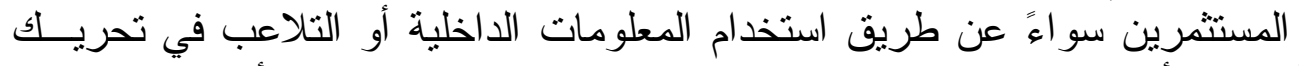

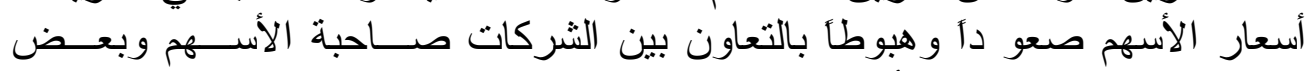

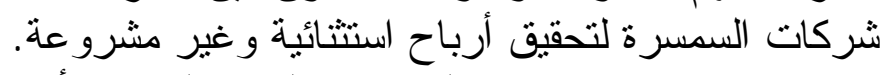

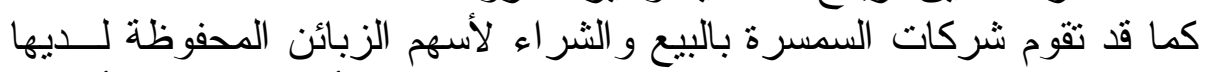

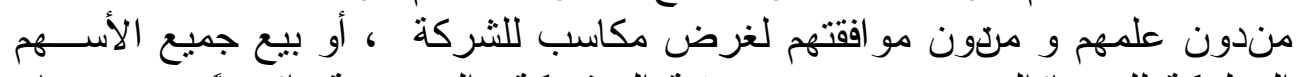

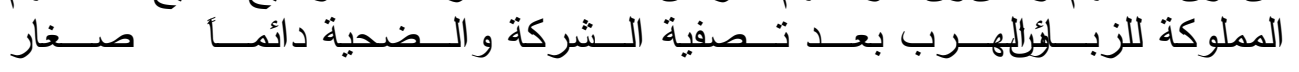
المسنتمرين.www.islamonline .net/Arabic/privacs

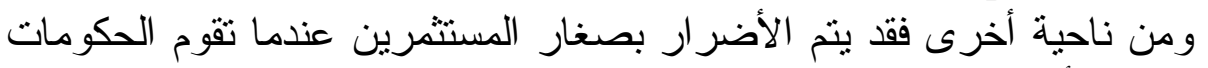

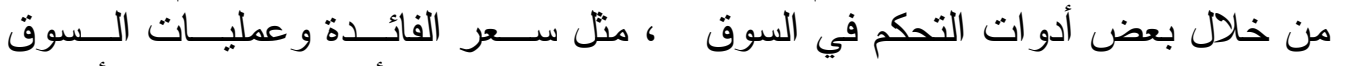

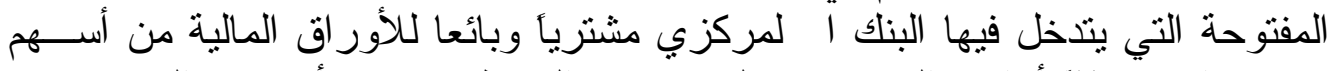

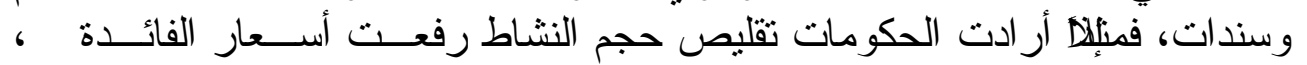

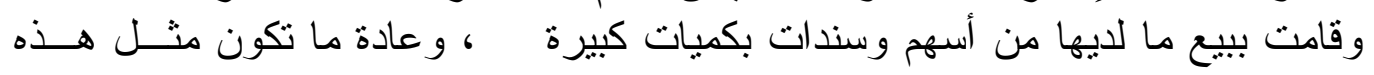

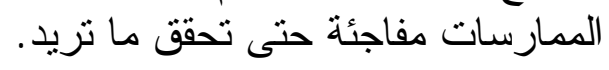

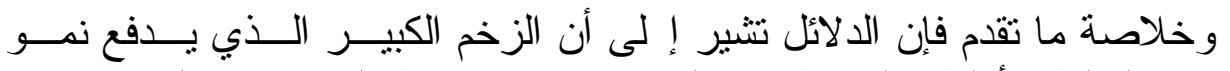

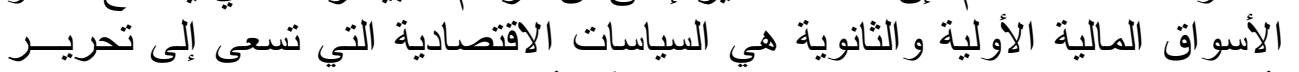

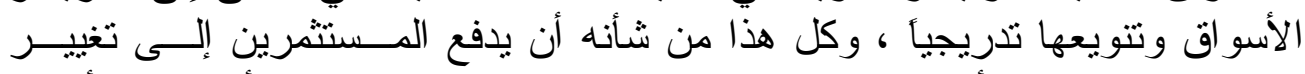

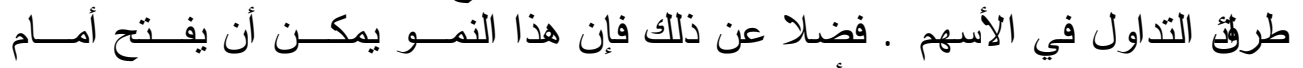

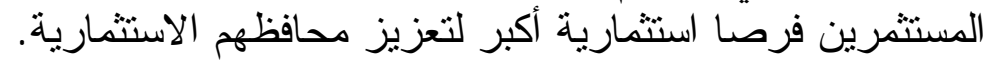

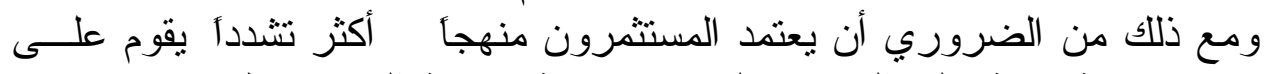

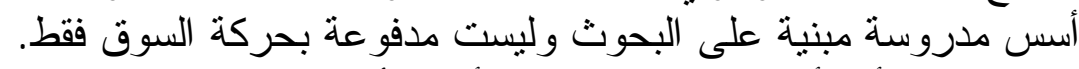

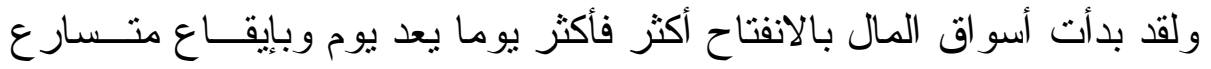

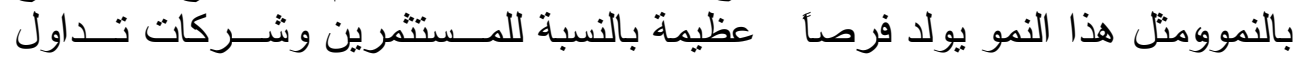


الأسهـهنه أيضا لا يخلو من الصعوبات و التحديات . كما أن هذه الأسواق تتحفز

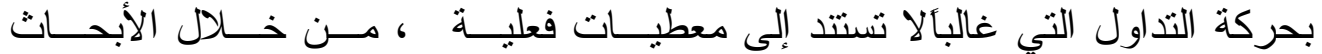

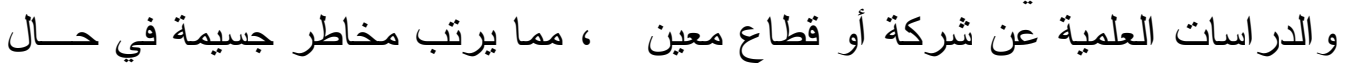
بدأت اتجاهات السوق بالتغبير أو التقلب.

\section{الجاتب التحليلي \\ وصف متغير ات البحث}

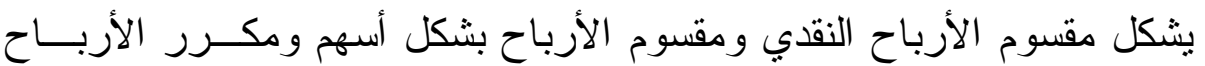

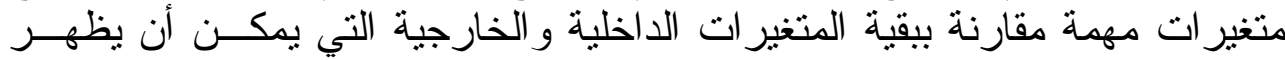

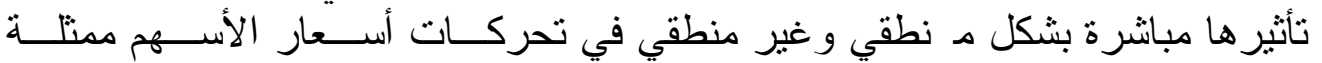
بمؤشر السوق.

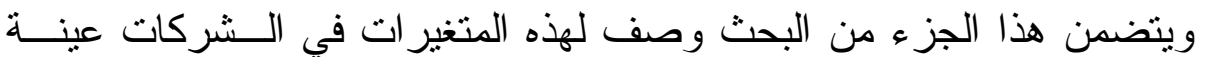
البحث وخلال الفترة المحددة للبحث. من لئ.

أولاً. محفظة السوق (مؤشر السوق للعينة)

\begin{tabular}{|c|c|c|c|c|c|c|c|c|c|c|}
\hline \multicolumn{11}{|c|}{ (المبالغ بالدنانير) } \\
\hline | السجاد & الخياطة & غازية & الهلاد & الخفيفة & الكيماوية & الإكترونية & الأصباغ & الار اجات & الشرقية & السنوات \\
\hline 18.33 & 19.35 & 60.3 & 25.1 & 22.24 & 45.82 & 50 & 37.37 & 33.45 & 34.46 & 1998 \\
\hline 19.46 & 23.15 & 104.1 & 46.06 & 37.81 & 65.41 & 65.27 & 59 & 56.38 & 43.7 & 1999 \\
\hline 13.38 & 14.17 & 84.34 & 39.5 & 44.43 & 57.69 & 49.81 & 57.73 & 76.3 & 45.84 & 2000 \\
\hline 16.95 & 18.89 & 82.92 & 36.89 & 34.83 & 56.31 & 55.03 & 51.37 & 55.38 & 41.33 & المتوسط \\
\hline
\end{tabular}

يتبين من الجدول r أن أعلى متوسط لأسعار الإغلاق الثهرية للفترة المحددة

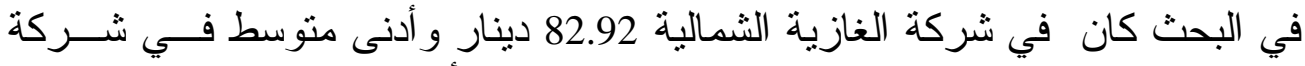

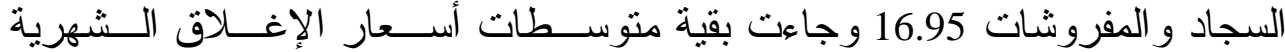

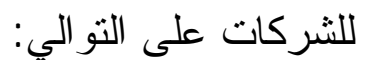

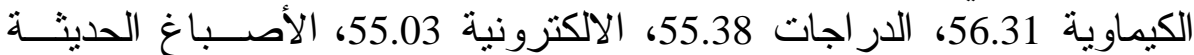

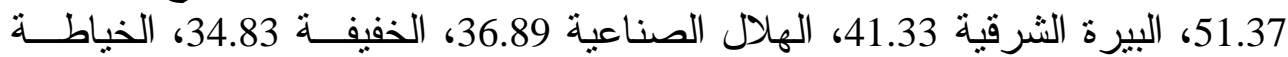

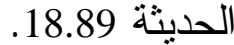

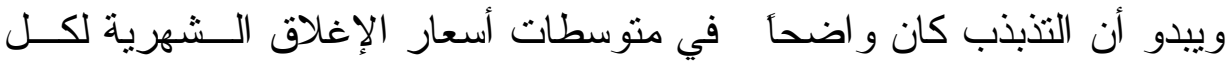
سنة من سنو ات البحث، مما قد يثير إلى إنعكاس أثنر بعض المتغير ات التئ في السوق. 


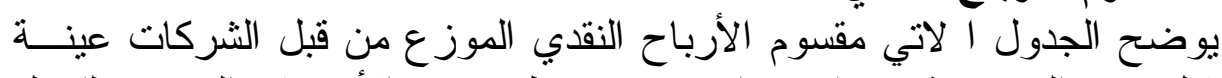

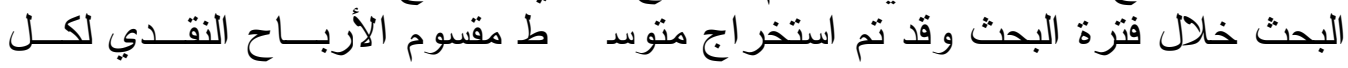

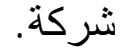

\begin{tabular}{|c|c|c|c|c|c|c|c|c|c|c|}
\hline \multicolumn{11}{|c|}{ مقسوم الأرباح النقدي للشركات عينة البحث } \\
\hline السجاد & الخياطة & شازية & الهلال & الخفيفة & الكيماوية & الأكترونية & الأصباغ & الاراجات & الثرقية & السنوات \\
\hline 150 & 75 & 168.75 & 348.8 & 300 & 270 & 200 & 975 & 38 & 80 & 1998 \\
\hline 250 & 150 & 135 & 500 & 1000 & 864 & 400 & 1170 & 152 & 120 & 1999 \\
\hline 250 & 120 & 250 & 1200 & 1400 & 1500 & 800 & 2047.5 & 304 & 262.5 & 2000 \\
\hline 217 & 115 & 184.6 & 683 & 900 & 878 & 467 & 1398 & 165 & 154.2 & المتوسط \\
\hline
\end{tabular}

يتضح من الجدول السابق أن أعلى منوسط مقسوم إرباح نقدية كان في شركة

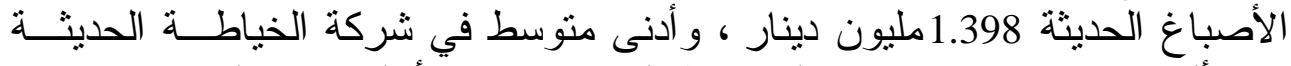

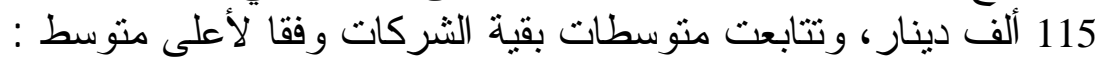

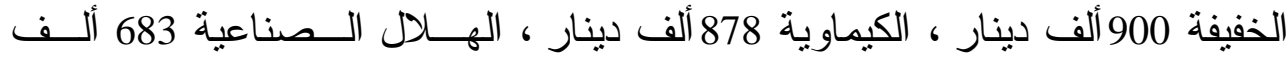

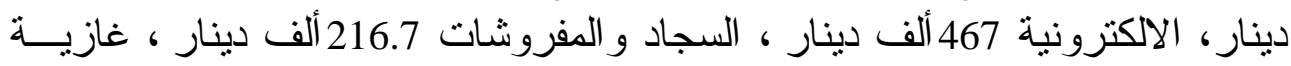

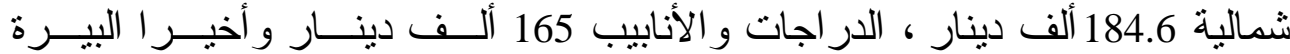
الثرقية 154.2 ألف دينار . ويلاحظ أيضا التصاعد في المقسوم النقدي في جميع الثركات خــال فتـرة البحث وبنسب متفاوتة.

\section{ثالثاً - مقسوم الأرباح بثكل أسهم}

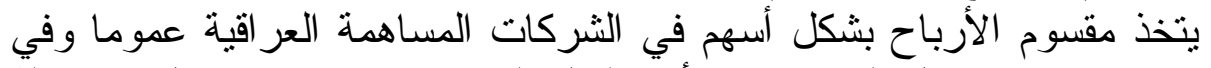

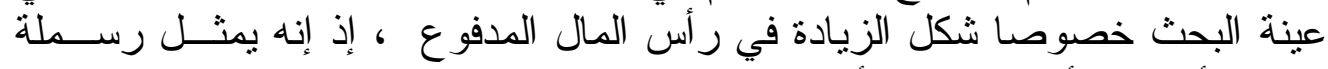
جزء أو كل الأرباح الحالية أو المحتجزة عن فئس فترة سابقة.

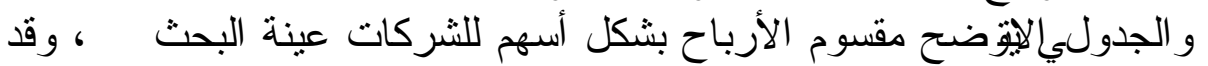

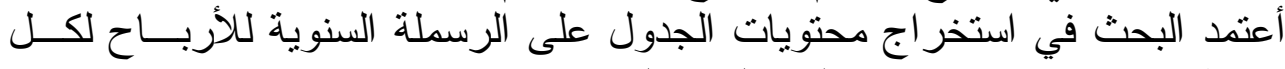
شركة ومن ثم أستخر اج موسطاتها لفترة البحث. 


\begin{tabular}{|c|c|c|c|c|c|c|c|c|c|c|}
\hline & ين الدنانب & المبالغ بم & ة البحة & كات عيا & دول ع للش & باح بشكل ال & سوم الأر & & & \\
\hline السجاد & الخياطة & شازية & الهلال & الخفيفة & الكيماوية & الإكترونية & الأصباغ & الدراجات & الثرقية & السنوات \\
\hline 42 & 28.5 & 22.5 & 93 & 100 & 135 & 92 & 195 & 22 & 40 & 1998 \\
\hline 50 & 150 & 182.5 & 521 & 200 & 270 & 200 & 195 & 76 & 40 & 1999 \\
\hline 125 & 50 & 200 & 356 & 300 & 730 & 400 & 9585 & 152 & 90 & 2000 \\
\hline 72.4 & 161.7 & 135 & 323.4 & 200 & 378.4 & 230.7 & 3325 & 83.3 & 56.7 & المتوسط \\
\hline
\end{tabular}

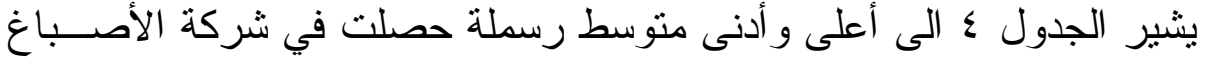

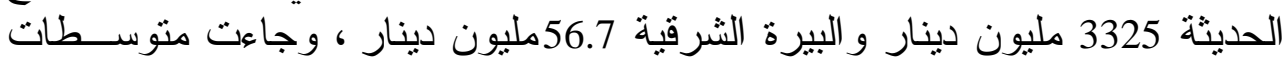
الرسملة للثركات الأخرى عينة البحث تناز ليا كما يأتي:

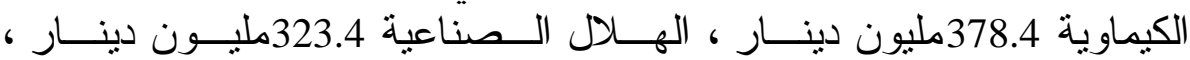

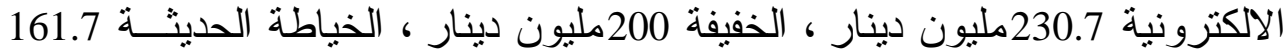

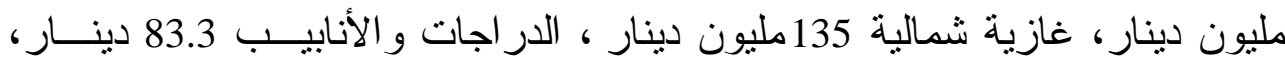

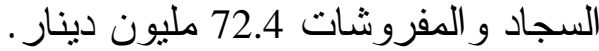
ويلاحظ أيضضى خلال الجدول التصاعد في عمليات الـ رسملة سنة بعد أخرى

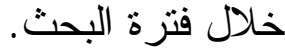

\section{رابعاً -مكرر (مضاعف) الربحية Pate Ratio}

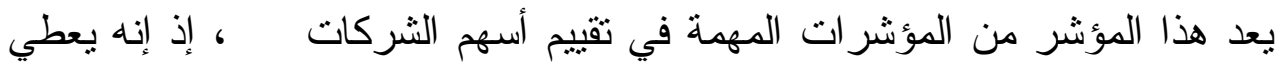

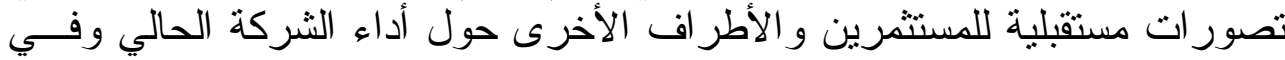

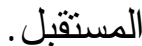

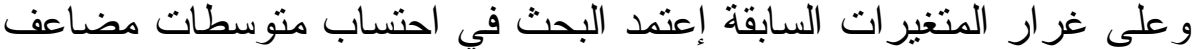

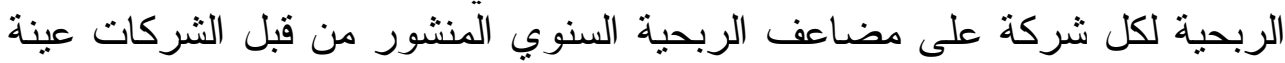

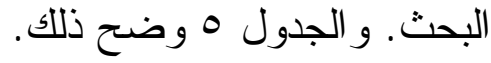




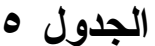

مكرر (مضاعف) الربحية للشركات عينة البحث

\begin{tabular}{|c|c|c|c|c|c|c|c|c|c|c|}
\hline السجاد & الخياطة & شازية & الهلال & الخفيفة & الكيماوية & الإكترونية & الأصباغ & الاراجات & الثرقية & السنوات \\
\hline 11.1 & 15 & 77 & 7.7 & 9.9 & 17.7 & 17.3 & 9.1 & 13 & 16.1 & 1998 \\
\hline 13.7 & 44.7 & 16.3 & 17.8 & 6.4 & 11 & 12.8 & 8.8 & 14.8 & 22.7 & 1999 \\
\hline 7.7 & 11.6 & 45.3 & 16.6 & 10.9 & 13.2 & 33.8 & 15 & 15.6 & 20 & 2000 \\
\hline 10.8 & 23.8 & 46.2 & 14 & 9 & 14 & 21.3 & 11 & 14.5 & 20 & المتوسط \\
\hline
\end{tabular}

تثتير متوسطات مضاعف الربحية إلى أن أعلى متوسط قد تحقق في شـــركة

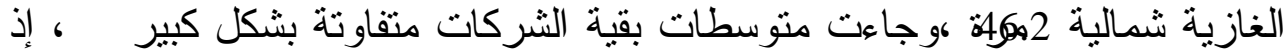

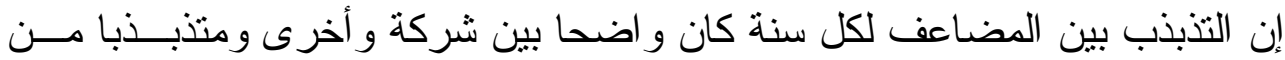

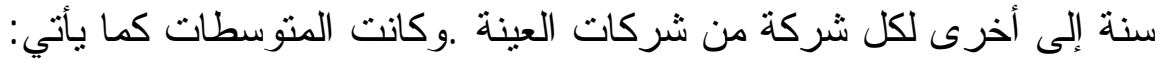

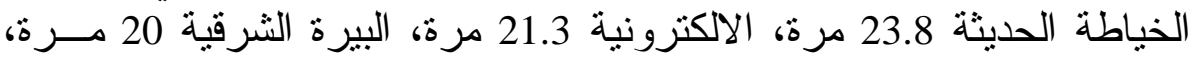

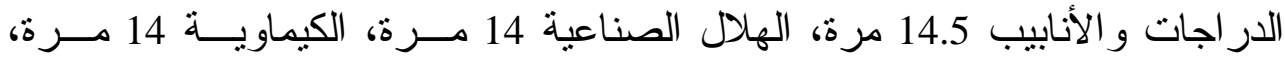
الأصباغ الحديثة 11 مرة، السجاد و الدفروشات 10.8 مرة، الخفيفة 9 مر ات.

\section{تحليل نتائج إختبار علاقات الارتباط والاحدار بين متغيرات البحث}

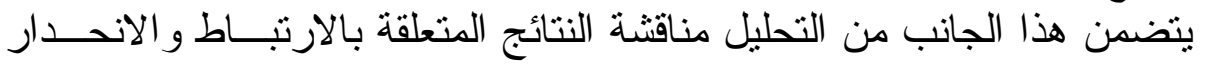
لمتغير ات البحث سو اء على مستوى كل شركة من الثركات و على مستوى العينـــة ككل : لمنير

أولاً تحليل نتائج علاقات الارتباط والاتحدار بين مقسوم الأرباح النقاي ومؤثــر

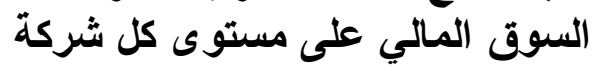

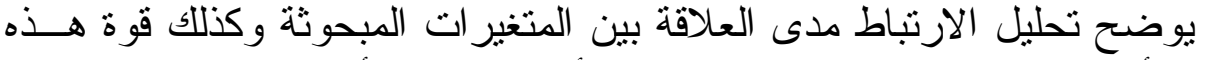

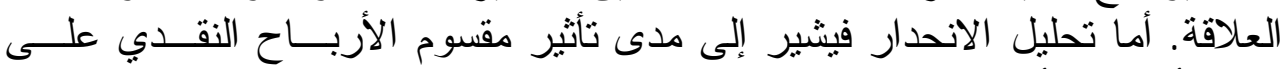

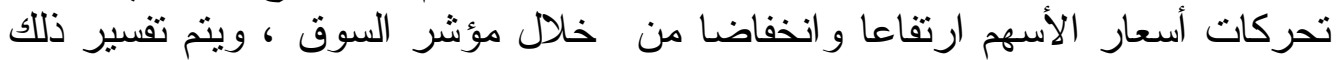

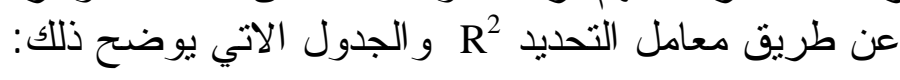




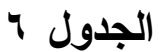

نتائج تحليل علاقات الارتباط والآحدار بين مقسوم الأرباح النقدي ومؤشر السوق

\begin{tabular}{|c|c|c|c|c|c|c|c|}
\hline المعنوية & $\mathbf{F}$ & معامل التحديد & الاحدار معامل & a الحد الثابت & $\mathbf{t}$ & الارتباط ro & الشركات \\
\hline 0.13 & 23.3 & 0.959 & 0.155 & 11.3 & 1.589 & 0.975 & السجاد \\
\hline 0.13 & 23.28 & 0.959 & 0.238 & 17.675 & 3.015 & 0.979 & الخياطة \\
\hline 0.981 & 0.001 & 0.001 & 4.622 & 44.146 & 1.494 & 0.03 & غازية شمالية \\
\hline 0.69 & 0.28 & 0.219 & 9.432 & 42.74 & 2.783 & 0.468 & الههل \\
\hline 0.364 & .2 .416 & 0.707 & 1.384 & 32.547 & 3.627 & 0.841 & الخفيفة \\
\hline 0.476 & 1.163 & 0.538 & 1.092 & 35.411 & 3.458 & 0.733 & الكيماوية \\
\hline 0.584 & 0.585 & 0.369 & 1.821 & 36.5 & 2.896 & 0.607 & الالكترونية \\
\hline 0.688 & 0.286 & 0.222 & 7.557 & 34.437 & 1.653 & 0.471 & الأصباغ \\
\hline 0.516 & 0.906 & 0.475 & 4.732 & 37.207 & 3.79 & 0.689 & الار اجات \\
\hline 0.663 & 0.342 & 0.255 & 4.822 & 37.565 & 2.636 & 0.505 & الثرقية \\
\hline
\end{tabular}

المصدر: الجدول من إعداد الباحث بالاستتاد إلى مخرجات الحاسوب

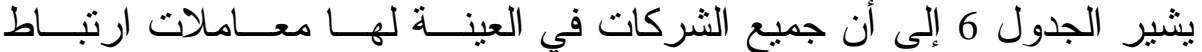

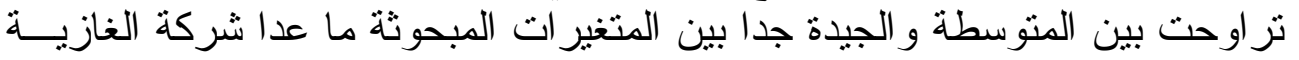

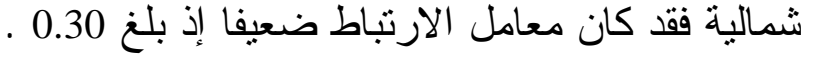

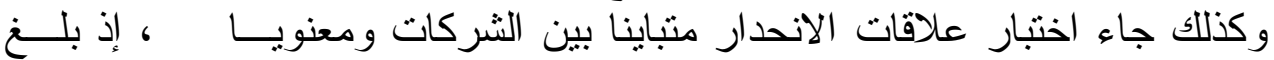

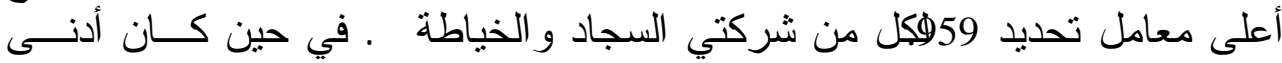

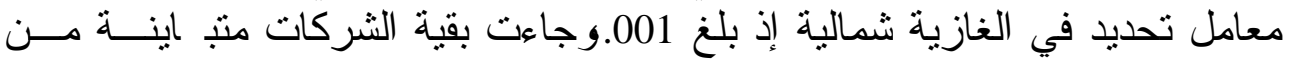

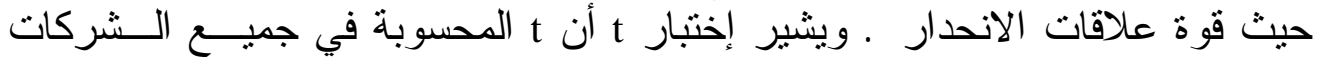

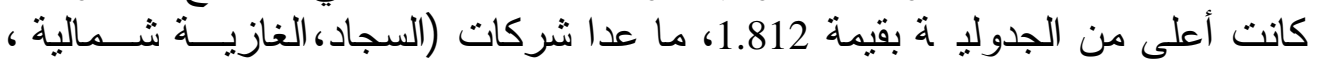

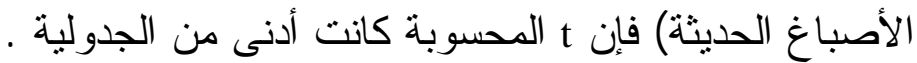

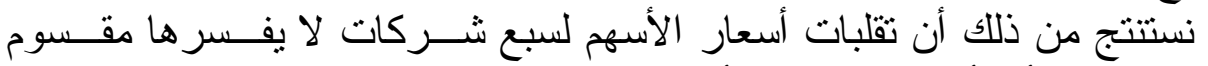

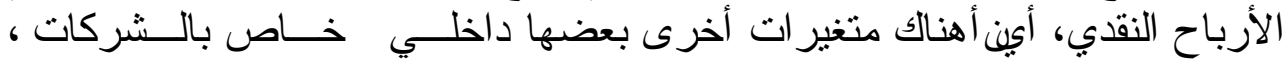

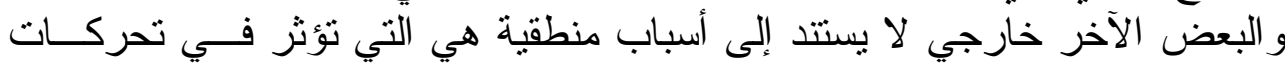

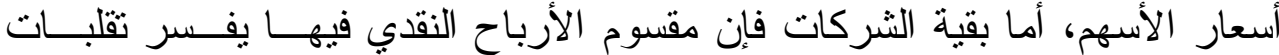

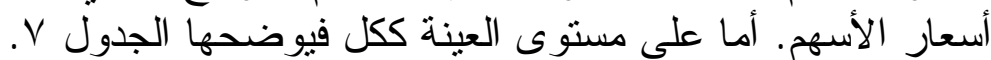




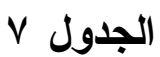

نتائج تحليل علاقات الارتباط والاتحدار بين مقسوم الأرباح النقدي ومؤشر السوق

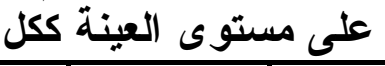

\begin{tabular}{|c|c|c|c|c|c|c|}
\hline $\begin{array}{c}\text { المعنوية } \\
\text { sig }\end{array}$ & F & $\begin{array}{c}\text { التحديد } \\
\mathbf{R}^{2} \\
\end{array}$ & الاحدار م معل & $\begin{array}{c}\text { الحد الثابت } \\
\alpha\end{array}$ & t & الارتباط معل \\
\hline 0.776 & 0.087 & 0.011 & 4.671 & 42.579 & 4.06 & 0.103 \\
\hline
\end{tabular}

المصدر: الجدول من إعداد الباحث بالاستتاد إلى مخرجات الحاسوب

يشير الجدول V إلى ضعف معامل الارتباط بــين مقـسوم الأربــاح النقــدي

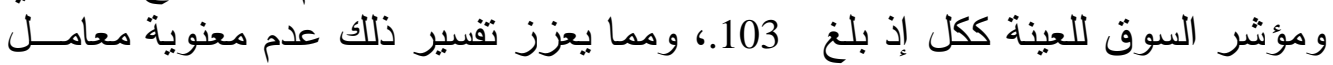

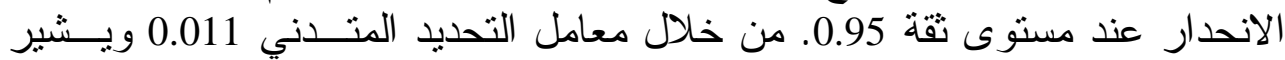

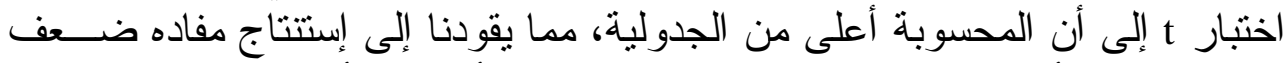

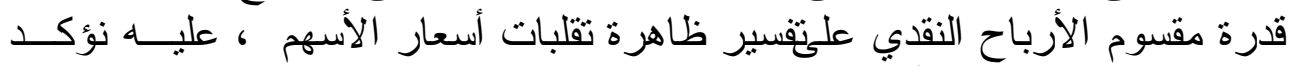

$$
\text { رفض فرضية البحث الأولى. }
$$

ثانياً - تعليل نتائج علاقات الارتباط والاتحدار بين مقسوم الأرباح بـشكل أســـهم

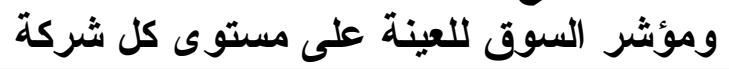

\section{الجدول}

نتائج تحليل علاقات الارتباط والاتحدار بين مقسوم الأرباح بشكل أسهم

$$
\text { ومؤشر السوق }
$$

\begin{tabular}{|c|c|c|c|c|c|c|c|}
\hline $\begin{array}{l}\text { المعنوية } \\
\text { sig }\end{array}$ & $\mathbf{F}$ & $\begin{array}{c}\text { التحديدمل } \\
\mathbf{R}^{2}\end{array}$ & الاحدار م معامل & الحد الثابت & $\mathbf{t}$ & الارتباط r" معامل & الثركات \\
\hline 0.763 & 0.153 & 0.133 & 4.475 & 41.016 & 3.326 & 0.364 & السجاد \\
\hline 0.431 & 1.552 & 0.608 & 0.011 & 36.608 & 4.463 & 0.78 & الخياطة \\
\hline 0.187 & 10.92 & 0.916 & 8.962 & 32.899 & 7.734 & 0.957 & غازية شمالية \\
\hline 0.12 & 27.66 & 0.965 & 4.169 & 31.52 & $\overline{10.799}$ & 0.982 & الههل \\
\hline 0.463 & 1.259 & 0.557 & 6.839 & 31.322 & 2.379 & 0.747 & الخفيفة \\
\hline 0.658 & 0.355 & 0.262 & 1.503 & 39.312 & 3.417 & 0.512 & الكيماوية \\
\hline 0.572 & 0.633 & 0.388 & 3.65 & 36.58 & 3.026 & 0.623 & الالكترونية \\
\hline 0.797 & 0.109 & 0.099 & 5.304 & 43.235 & 4.868 & 0.314 & الأصباغ \\
\hline 0.525 & 0.852 & 0.46 & 9.514 & 37.07 & 3.636 & 0.678 & الدر اجات \\
\hline 0.797 & 0.109 & 0.099 & 9.961 & 39.354 & 2.129 & 0.314 & البيرة الثرقية \\
\hline
\end{tabular}

يبين لنا الجدول ^ نباين معاملات الارنباط والانحدار بين مقـسوم الأربــاح

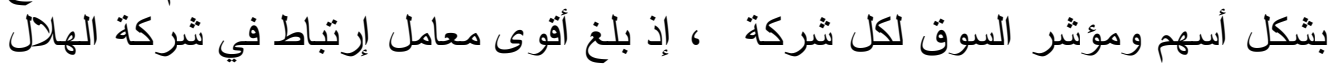




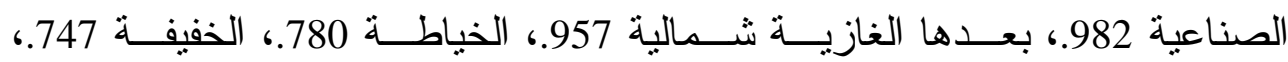

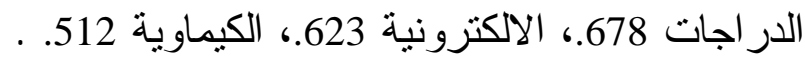

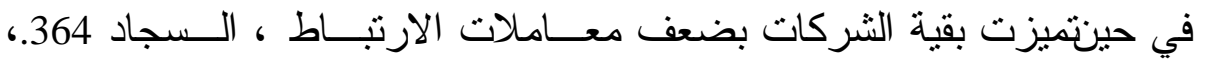

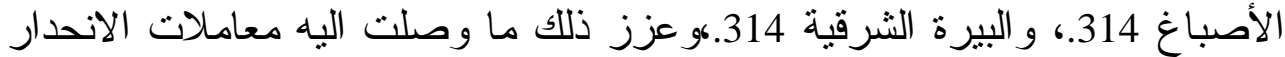

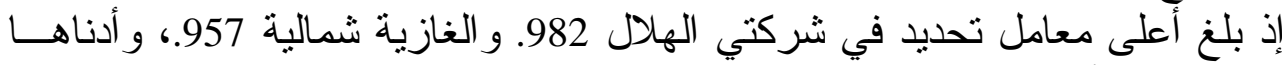

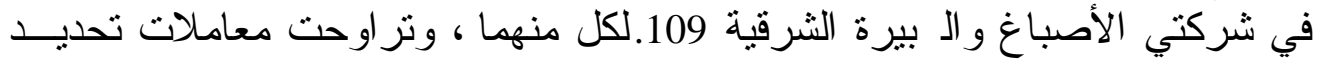
بقية الشركات بين ذلك .

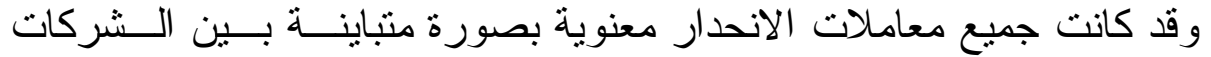

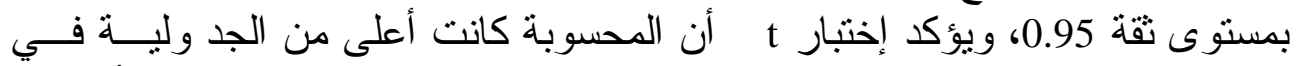

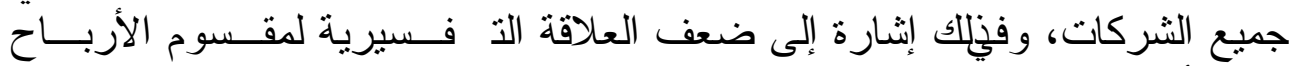

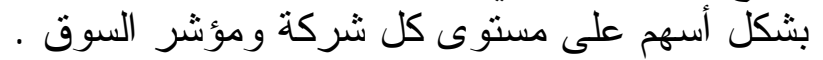
من جهة أخرى وعند اختبار المتغير ات نفسئها على مستى فئوى العينة ككل تظهر

$$
\text { نتائج موضحة في الجدول } 9 .
$$

\section{الجدول 9}

نتائج تحليل علاقات الارتباط والاتحدار بين مقسوم الأرباح بشكل أسهم ومؤشر السوق على مستوى العينة ككل

\begin{tabular}{|c|c|c|c|c|c|c|}
\hline $\begin{array}{c}\text { المعنوية } \\
\text { sig }\end{array}$ & $\mathbf{F}$ & $\begin{array}{c}\text { التحديدمل } \\
\mathbf{R}^{2}\end{array}$ & الاحدار م معل & الحد الثابت & $\mathbf{t}$ & الارتباط معلمل \\
\hline 0.723 & 0.134 & 0.017 & 2.524 & 43.736 & 5.935 & 0.129 \\
\hline
\end{tabular}

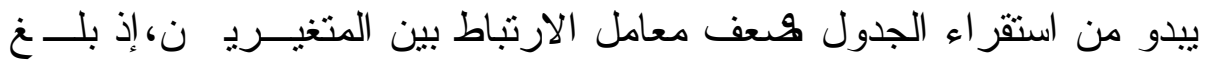

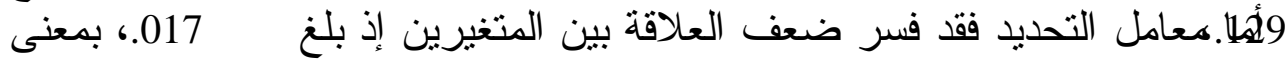

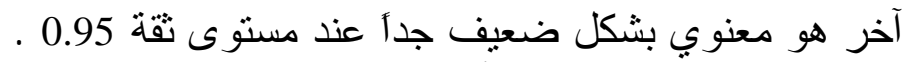

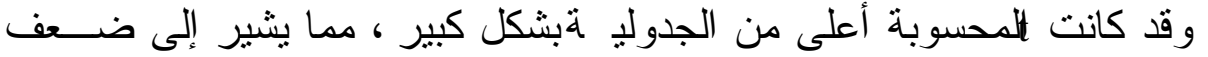

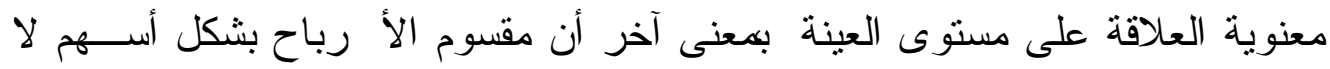
يفسر التقلبات، عليه ترفض الفرضية الثانية . 


\section{P/E الثاً - نتائج تحليل علاقات الارتباط و الاحدار بين مكرر (مضاعف) الربحية} Ratio ومؤشر السوق علان الارت

\begin{tabular}{|c|c|c|c|c|c|c|c|}
\hline \multicolumn{8}{|c|}{ الجدول · 1} \\
\hline $\begin{array}{l}\text { المعنوية } \\
\text { sig }\end{array}$ & $\mathbf{F}$ & 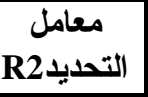 & الاحصدار B معل & الثابت & $\mathbf{t}$ & re" الارتباط re & الشركات \\
\hline 0.923 & 0.015 & 0.015 & 0.369 & 40.993 & 1.221 & 0.121 & السجاد \\
\hline 0.596 & 0.541 & 0.351 & 0.298 & 37.917 & 3.338 & 0.593 & الخياطة \\
\hline 0.187 & 10.94 & 0.916 & -0.289 & 58.34 & 12.742 & 0.957 & غازية شمالية \\
\hline 0.061 & 109.5 & 0.991 & 1.653 & 21.808 & 9.366 & 0.995 & الهلد \\
\hline 0.672 & 0.32 & 0.242 & -1.908 & 62.299 & 1.992 & 0.492 & الخفيفة \\
\hline 0.079 & 64.71 & 0.985 & -2.662 & 82.172 & 17.438 & 0.992 & الكيماوية \\
\hline 0.927 & 0.013 & 0.013 & 9.457 & 42.984 & 2.258 & 0.114 & الالكترونية \\
\hline 0.824 & 0.08 & 0.074 & 0.715 & 37.158 & 1.301 & 0.273 & الأصباغ \\
\hline 0.324 & 3.206 & 0.762 & 6.005 & -41.876 & -0.861 & 0.873 & الدر اجات \\
\hline 0.137 & 21.02 & 0.955 & 2.697 & -7.864 & -0.676 & 0.977 & البيرة الثرقية \\
\hline
\end{tabular}

يظهر الجدول · أن هناك اختلاف أ بيننطوذج مكرر الأرباح و الإِ نمــوذجين

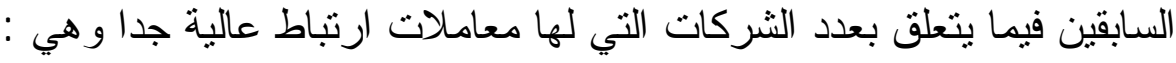

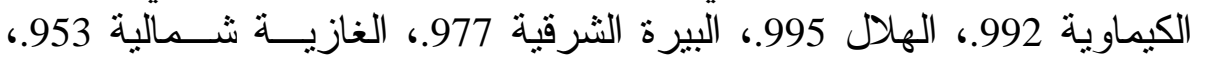

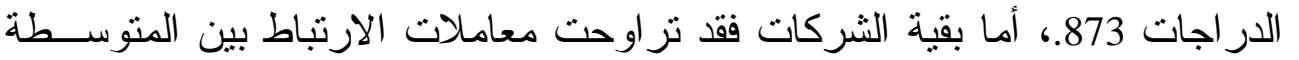

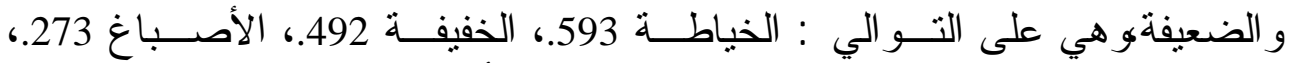

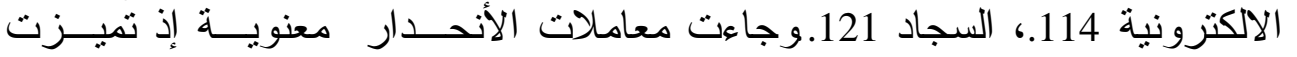

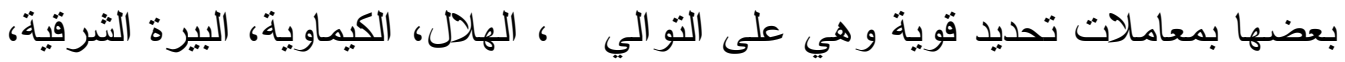

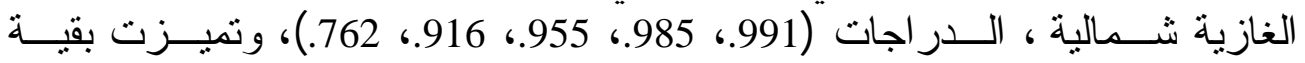

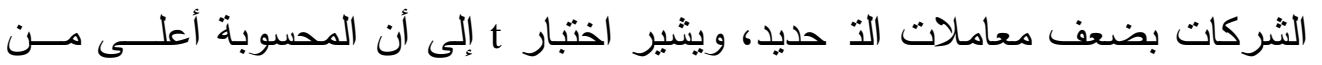

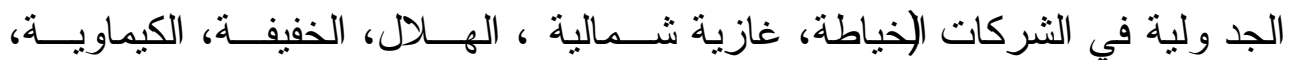

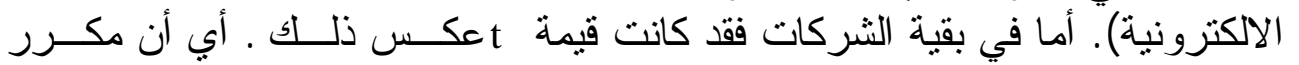

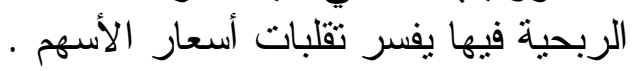

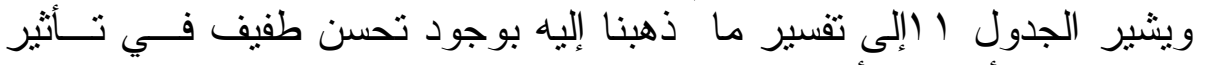

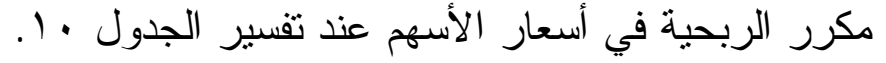




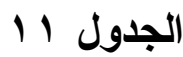

نتائج تحليل علاقات الارتباط والاحدار بين مكرر الربحية ومؤشر السوق على مستوى العينة ككل مكرن الإلين

\begin{tabular}{|c|c|c|c|c|c|c|}
\hline $\begin{array}{c}\text { المعنوية } \\
\text { sig }\end{array}$ & $\mathbf{F}$ & $\begin{array}{c}\text { التحديد } \\
\mathbf{R}^{2}\end{array}$ & الاحددار B معل & $\begin{array}{c}\text { الحد الثابت } \\
\text { الثاب }\end{array}$ & $\mathbf{t}$ & 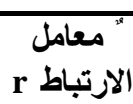 \\
\hline 0.07 & 4.371 & 0.353 & 1.071 & 25.221 & 2.327 & 0.594 \\
\hline
\end{tabular}
المصدر: الجدول من إعداد الباحث بالاستتاد إلى مخرجات الحاسوب

يوضح الجدول ل1 إرتفاع معامل الارتباط على مستوى العينة ككل وكــللك

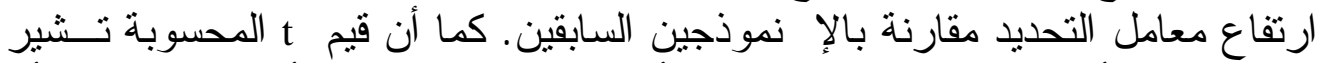

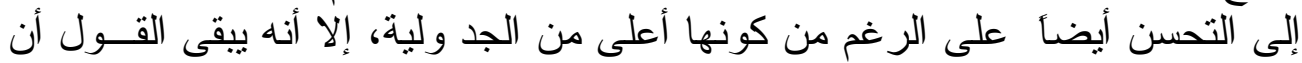

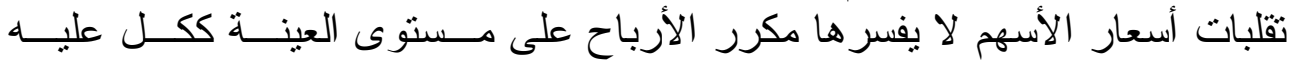
ترفض الفرضية الثالثة.

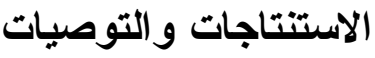

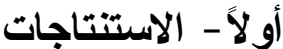

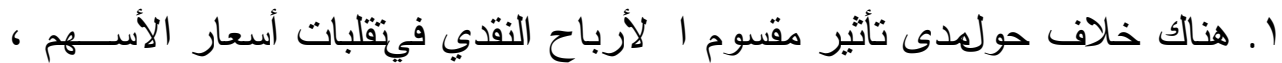

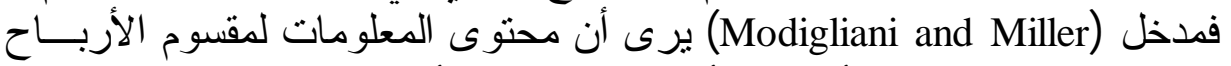

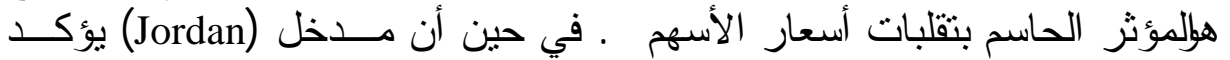

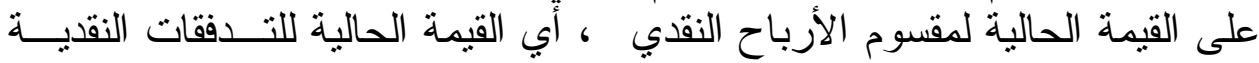

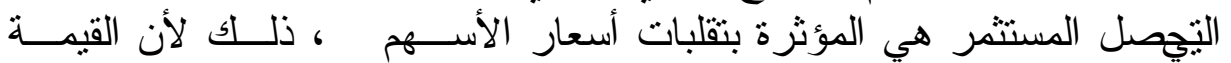
الحالية للمقسوم تعد بمثابة دخل للمستثمر من دون أن يؤثر ذلإن اللك فـي رأســماله r. ضعف قلي. الاصلية مقسوم الأرباح النقدي ومقسوم الأرباح بشكل أسهم ومكرر الربحية

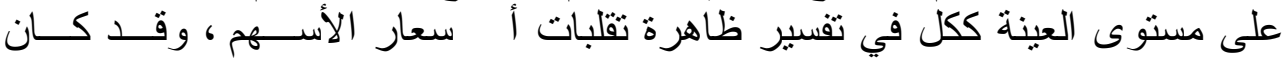

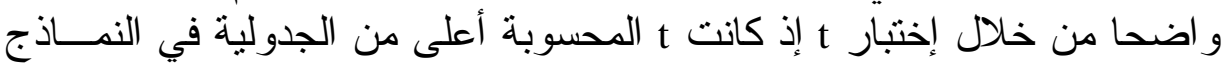

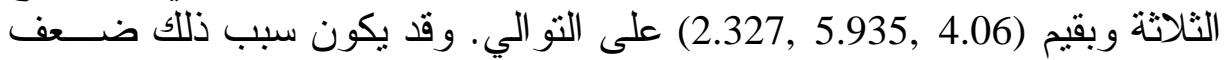
كفاءة سوق العر اق للأور اق المالية، كما تم إثباته فــي در اســـة (الحســناوي، . (199V

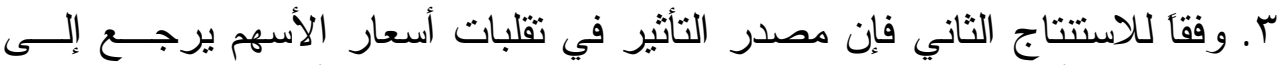

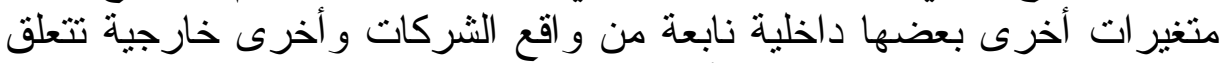

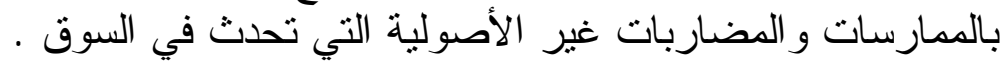




\section{ثانياً - التوصيات}

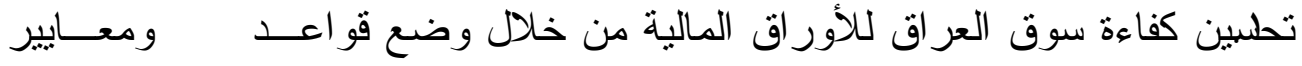

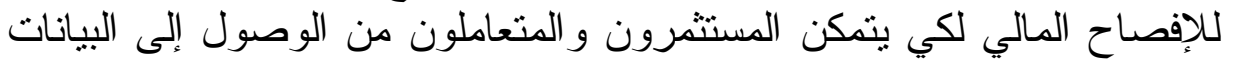

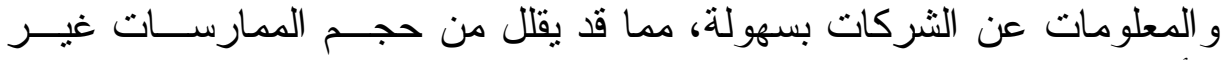

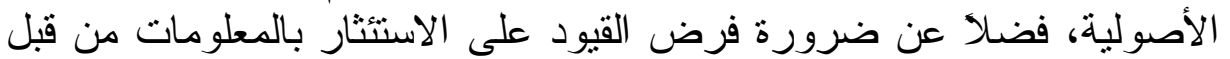

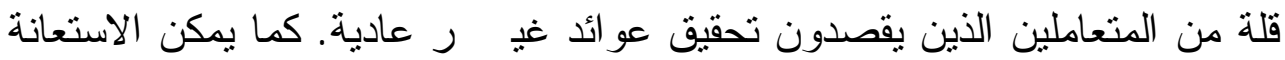

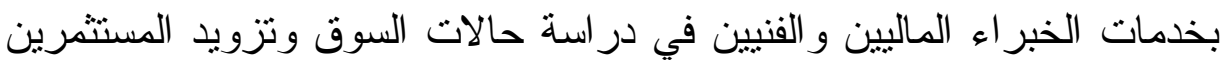

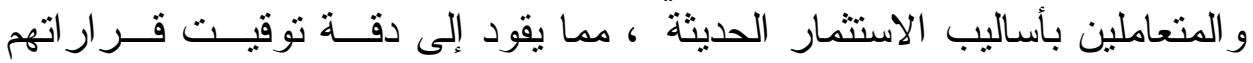
الاستثمارية.

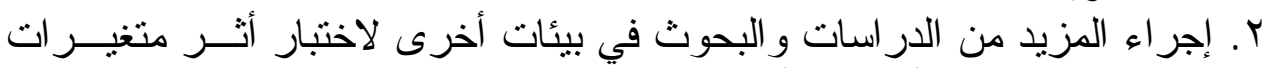
مختلفة على تقلبات أسعار الأسهر.

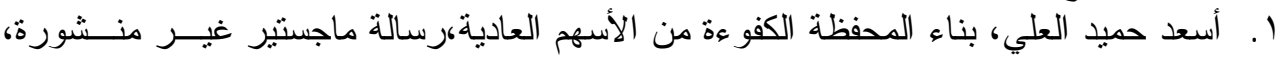

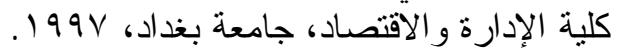

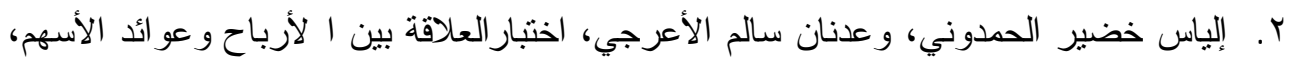

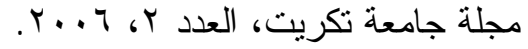

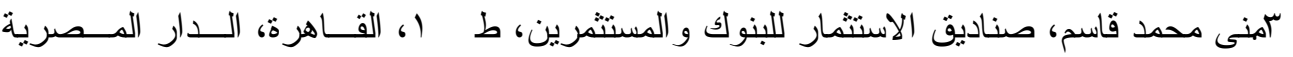

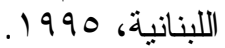

\section{ثانياً - المر اجع باللغة الإنكليزية}

1. Branch, Ben, Investment, Principles and practices $2^{\text {nd }}$ ed., long man publishing, snc,U.S.A, 1989.

2. William, Edward E,Investment analysis ,10th. Ed., prentice-Hall,Inc., U.S.A., 1974.

3. Amling, Frederick,1974, Investment an Introduction to analysis and Management, 3rd. Ed., U.S.A.

4. Francis, Jack,Investment analysis and Management, Grow-Hill,Inc.,U.S.A,1991.

5. Jahnke,gregg, Klaffk, Stephen J. And Harry R.,Price Earning Ratios and security performance,Journal of portfolio Management,vol. 4, No.1, 1987.

6. Francis, Jack, Investment, Analysis and Management, McGraw-Hill, Inc., U.S.A, 1982.

7. Hampton John, J., Financial Decision Making , $4^{\text {th }}$,.ed., prentice-Hall of India, 1996.

8. Petty, J, William, Keown, Arthur J., and Scott J.,Basic Financial Management, $2^{\text {nd }}$.ed ., Prentice -Hall. Inc., printed in U.S.A, 1982.

9. Van Horn, James c., Fundamental of financial management, $6^{\text {th }}$.ed., prentice-Hall ,Inc., U.S.A, 1986.

10.Weston,J. Fred and Brigham ,F.Eugene,Managerial Finance, Seventh edition,1981 .

11.www.albayan.co.ae/albayan/2003/03/28/egt/35.htm.

12.Francis ,Jack Clark, Management of Investment, Japan: McGraw-Hill, Inc, 1983.

13. Spreacher,c. Ronald,Essential of Investment, Honghton Mifflin Company,U.S.A,1979.

14. www.islamonline.net/arabic/sitemap.htm.

15. www.exchangenewyork.com/.

16. www.thegulfbiz.com/vb/showwth.

17. wwwarabiyat.com/forums/foru...php? .

18. www.gulfbase.com/home ar.asp. 